\section{DEVELOPMENT OF TEST METHODS TO DETERMINE THE COMPATIBILITY OF LIQUID HAZARDOUS MATERIALS WITH POLYETHYLENE PACKAGINGS}

J. M. Crissman

M. A. Schen

U.S. DEPARTMENT OF COMMERCE Nathonal Instrurte of Standards and Technology Materlab Sclence and Englneering Laboratory Polymers Dlviston

Calthersburg, MD 20899

Prepared for

U.S. Department of Transportation Research and Speclal Programs Administration Office of Hazardous Materials Transportation
U.S. DEPARTMENT OF COMMERCE Robert A. Mosbacher, Secretary NATIONAL INSTITUTE OF STANDARDS AND TECHNOLOGY

John W. Lyons, Dir octor

$-Q C$

100

.456

\#4729 

NISTIR 4729

\section{DEVELOPMENT OF TEST METHODS TO DETERMINE THE COMPATIBILITY OF LIQUID HAZARDOUS MATERIALS WITH POLYETHYLENE PACKAGINGS}

J. M. Crissman

M. A. Schen

U.S. DEPARTMENT OF COMMERCE National Institute of Standards and Technotogy Materlals Sclence and Englneering Laboratory

Polymers Division

Galthersburg, MD 20899

Prepared for

U.S. Department of Transportation Research and Speclal Programs

Administration

Office of Hazardous Materials

Transportation

Decomber 1991

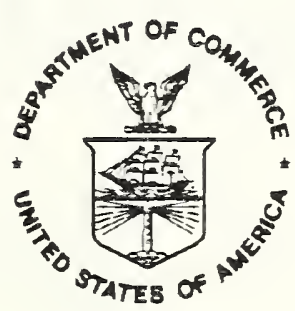

U.S. DEPARTMENT OF COMMERCE Robert A. Mosbacher, Secretary NATHNAL INSTITUTE OF STANDARDS AND TECHNOLOGY

John W. Lyons, Director 



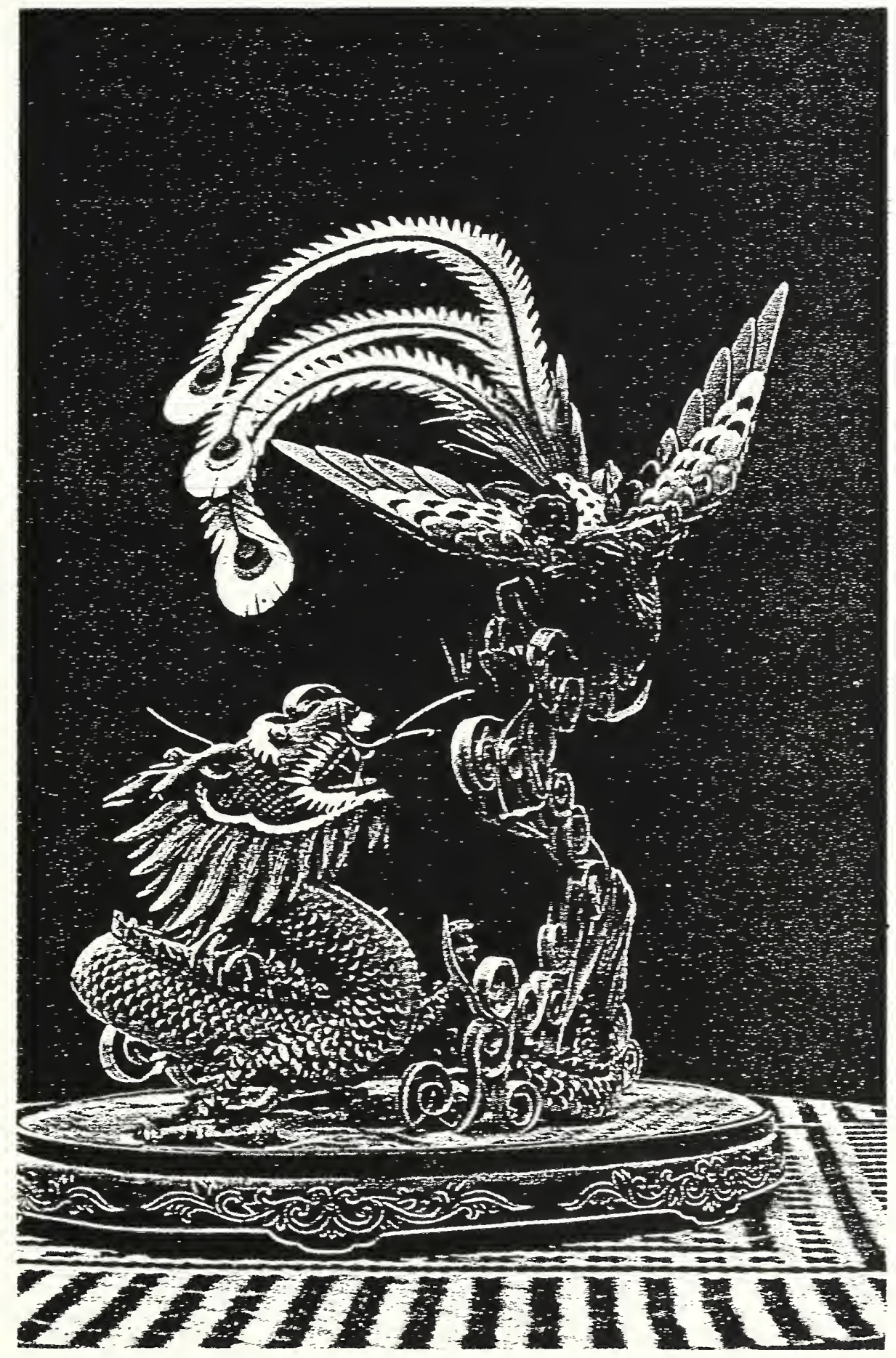

Dragon and phoenix, a symbol of compatibility. 



\section{Notice}

Certain commercial materials and equipment are identified in this report in order to specify adequately the experimental procedures. In no case does such an identification imply recommendation or endorsement by NIST, nor does it imply the best available for the purpose. 


\begin{abstract}
$\underline{\text { Abstract }}$
This report describes work done for the Department of Transportation, Office of Hazardous Materials Transportation, to develop test methods which can be used to determine whether a liquid hazardous material may be shipped in a specific type of polyethylene container. Current federal regulations require that each prospective lading be tested individually in proposed polyethylene packagings. The central task of this project is to determine the feasibility of substituting a set of standard liquids for the purpose of compatibility testing with polyethylene. In determining the compatibility of hazardous liquids with polyethylene there are three major areas of concern, permeation and/or swelling, environmental stress cracking, and oxidative degradation. Specific recommendations are made for a set of standard liquids which address all three aspects of compatibility. Special attention is given the class of organic peroxides which may be unstable at the test temperatures currently in use. In the area of permeation, an empirical method known as the "Permachor" scheme is proposed as a means of estimating the permeability of many liquid hazardous materials, and for ranking individual members within a given class of liquids.
\end{abstract}

Key words: Compatibility, hazardous materials, organic peroxides, Permachor, permeation, polyethylene, standard liquid. 


\section{TABLE OF CONTENTS}

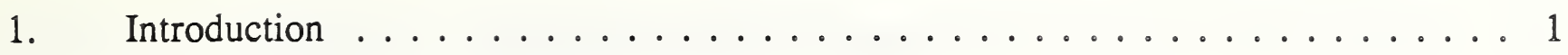

1.1 Comparison of DOT and European Regulations $\ldots \ldots \ldots \ldots \ldots \ldots$

1.2 Diluents Used in the Shipping of Organic Peroxides . . . . . . . . . . . . . 3

1.3 Permeation of Organic Liquids Through Polyethylene . . . . . . . . . . . . 4

1.4 A Test for Stress Cracking $\ldots \ldots \ldots \ldots \ldots \ldots \ldots \ldots \ldots$

2. Compatibility Testing for Permeation and/or Swelling ........... 5

2.1. Candidate Materials as Standard Liquids . . . . . . . . . . . . . . . 5

2.2. Experimental Work in Support of the Permachor Scheme ... . . . . . . . . 13

3. Test Methods to Evaluate the Stress Cracking of Polyethylene ... . . . . . 20

4. Compatibility Testing Procedures for Organic Peroxides . . . . . . . . . . . 26

4.1. Commercial Organic Peroxides: Formulations and Plastics Packaging . . . . . 26

4.1 .1 Classification of Organic Peroxides . . . . . . . . . . . . . 27

4.1 .2 Polyethylene Packaging of Organic Peroxides . . . . . . . . . . . . . 27

4.1.3 Currently Implemented Compatibility Testing Methods . . . . . . . . . . . . . 30

4.2 Permeation through Polyethylene $\ldots \ldots \ldots \ldots \ldots \ldots \ldots$

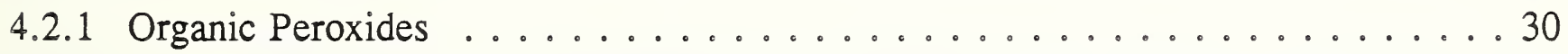

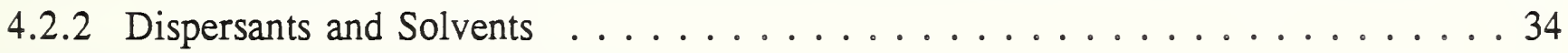

4.3 Peroxide Chemistry and Decomposition Pathways . . . . . . . . . . . . 37

4.3 .1 Compound Stability $\ldots \ldots \ldots \ldots \ldots \ldots \ldots \ldots \ldots \ldots$

4.3.2 Homolytic and Catalytic Decomposition and Radical Reactivity . . . . . . . . 37

4.3.3 Polyethylene Cross-linking using Organic Peroxides . . . . . . . . . . . . . . 41 
4.4 Free Radical Oxidation of Polyethylene ... . . . . . . . . . . 41

4.4 .1 Radical Attack on Unstabilized Polyethylene . . . . . . . . . . . . 42

4.5 Physical Factors Affecting Polyethylene Oxidative Stability ... . . . . . . 46

4.5.1 Morphology, Oxygen Absorption and Permeability $\ldots \ldots \ldots \ldots$....... 46

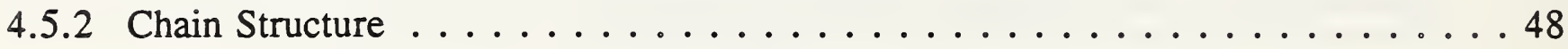

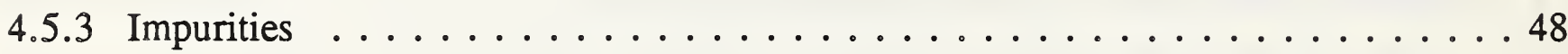

4.6 Oxidative Stabilization of Polyethylene . . . . . . . . . . . . . . . 49

4.6 .1 Classification of Antioxidants $\ldots \ldots \ldots \ldots \ldots \ldots$. . . . . . . 49

4.6 .2 Compounding with Polyethylene $\ldots \ldots \ldots \ldots \ldots \ldots \ldots \ldots \ldots \ldots \ldots \ldots$

4.7 Assessing Polyethylene Oxidation $\ldots \ldots \ldots \ldots \ldots \ldots \ldots \ldots \ldots \ldots \ldots \ldots \ldots$

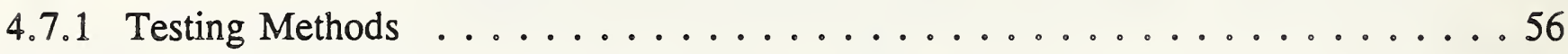

5. Discussion of the European Test Methods ................. 57

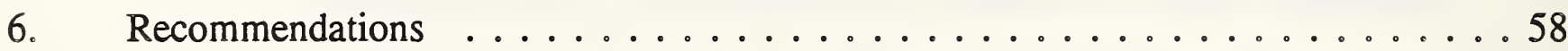

6.1. Compatibility Testing for Permeation and/or Swelling ... . . . . . . 59

6.2 Test Methods to Evaluate the Stress Cracking of Polyethylene .......... 60

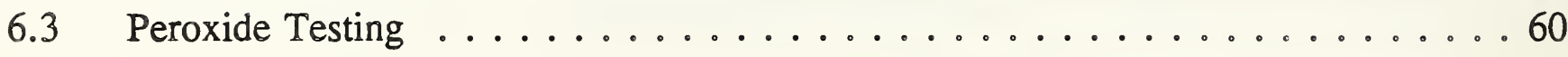

6.3 .1 Failure Prediction Due to Peroxide Induced Oxidation $\ldots \ldots \ldots \ldots$

6.3 .2 Permeation of Organic Peroxides and their Solvents . . . . . . . . . 61

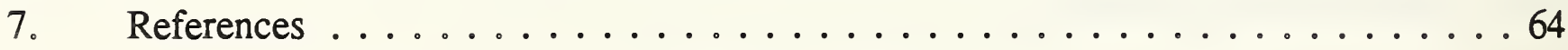




\section{LIST OF TABLES}

Table 2.1 Properties of Flammable Organic Liquids . . . . . . . . . . . . . . . 6

Table 2.2 Candidate Materials for use as Standard Liquids . . . . . . . . . . . 11

Table 2.3 Permachor $(\pi)$ Values for Estimating P-Factors . . . . . . . . . . . 12

Table 2.4 Permeation Factors for Twenty-Two Organic Liquids . . . . . . . . . . . 14

Table 2.5 Physical Properties of Mineral Spirits . . . . . . . . . . . . . 18

Table 2.6 Permeation Data for Various Types of Minearl Spirits . . . . . . . . . . 19

Table 3.1 ESCR Test Results using ASTM D $1693 \ldots \ldots$. . . . . . . . . . 25

Table 4.1 Classification of Organic Peroxides . . . . . . . . . . . 28

Table 4.2 Permachor $(\pi)$ Values and Thermal Stability Data for Lowest Peroxide Family Members . . . . . . . . . . . . . . . . . 32

Table 4.3 Calculated Permachor $\pi$-Values for Select Solvents Used for the Marketing of Commercial Organic Peroxides . . . . . . . . . . . . 35

Table 4.4 Ten-Hour Half-life Temperatures ${ }^{(2)}$ and Radical Type Formed for the Thermal Decomposition of Organic Peroxides according to Peroxide Class . . . . . . . . . . . . . . . . . . . . 38

Table 4.5 Relative Reactivity of Radicals . . . . . . . . . . . . . . . . . . 39

Table 4.6 Solubility and Diffusion of Oxygen in Polyethylene at $25^{\circ} \mathrm{C} \ldots \ldots \ldots 47$

Table 4.7 Typical Chain-Breaking (CB) and Combined Chain-Breaking/UV Stabilizing (CB/UV) Antioxidants . . . . . . . . . . . . . . . 52

Table 4.8 Commercial Antioxidants . . . . . . . . . . . . . . 53 


\section{LIST OF FIGURES}

Figure 2.1 Flash point versus Permachor number for more than 100 organic

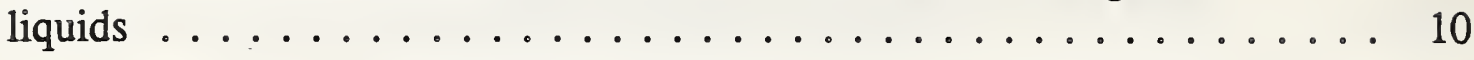

Figure 2.2 Permeation factor versus Permachor number at $23^{\circ} \mathrm{C} \ldots \ldots \ldots \ldots$

Figure 2.3 Permeation factor versus Permachor number at $50^{\circ} \mathrm{C} \ldots \ldots \ldots \ldots$

Figure 2.4 Permeation factor versus Permachor number at $60^{\circ} \mathrm{C} \ldots \ldots \ldots \ldots$

Figure 3.1 Hours to failure versus temperature from ESCR tests on four types of

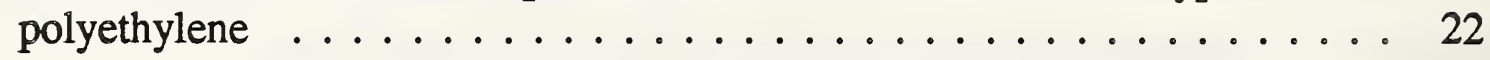

Figure 3.2 Hours to failure versus applied stress for specimens having varied thickness and bend radius . . . . . . . . . . . . . 23 


\section{INTRODUCTION}

This report describes work done under reimbursable agreement DTRS-56-90-x-70006 for the Department of Transportation (DOT), Office of Hazardous Materials Transportation (OHMT). The objective of this work is to develop practical and cost-effective test methods which can be used to determine whether a liquid hazardous material may be shipped in a specific type of polyethylene packaging. It is anticipated that the results obtained from this project will enable the OHMT to amend Title 49 CFR so that the assessment of chemical compatibility of polyethylene packagings can be improved.

The National Institute of Standards and Technology (NIST) has been requested to address the following tasks:

Task 1. Develop a test program to evaluate the compatibility of liquid hazardous materials with polyethylene packagings based on generic groupings of materials.

The following subtasks will be performed:

(1) Review the current DOT test requirements to see if they can be modified to accomplish Task 1.

(2) Review the European (ADR/RID) approach to testing and compare with the DOT methods. If laboratory work is necessary, submit a work plan, including a cost estimate, to OHMT for review and approval; and

(3) Recommend testing procedures based on groupings of hazardous liquids which can be used as a basis for rulemaking.

Task 2. Develop a compatibility test procedure for liquids that are unstable at $21^{\circ} \mathrm{C}\left(70^{\circ} \mathrm{F}\right)$ using organic peroxides as a basis for the work.

The following subtasks will be performed:

(1) Contact the manufacturers of organic peroxides to determine how they are testing peroxides which are unstable at $21^{\circ} \mathrm{C}$ for compatibility with polyethylene packagings.

(2) Review the literature to ascertain the current state of knowledge concerning the compatibility of organic peroxides with polyethylene packagings. 
(3) Develop guidelines which might be used to predict the compatibility of organic peroxides with polyethylene packagings; and

(4) Evaluate the possibility of using materials other than organic peroxides to predict the compatibility of organic peroxides with polyethylene packagings. It is envisioned that this type of testing would be done at $21^{\circ} \mathrm{C}$ even though the peroxide might be shipped under refrigeration. If laboratory work is necessary, submit a work plan, including a cost estimate, to OHMT for review and approval.

TASK 3. Devise compatibility testing procedures using standards liquids.

The following subtasks are to be performed:

(1) Compile a list of experimentally determined permeation factors for a wide range of substances which swell and permeate polyethylene.

(2) Identify the lowest molecular weight compounds within each major group of substances which can be expected to be shipped in polyethylene packagings.

(3) Calculate the permeation factor using the Permachor numbers for the materials identified in Subtask 3(2).

(4) Devise compatibility testing procedures using a set of standard liquids which evaluate the swelling, permeation, and stress cracking of polyethylene packagings.

TASK 4. Devise compatibility testing procedures for organic peroxides.

The following subtasks are to be performed:

(1) Evaluate the organic peroxide based degradation of, and the effects of added antioxidants on, polyethylenes used in the packaging of organic peroxides.

(2) Select, through testing, a candidate organic peroxide and diluent which show the greatest aggressiveness towards polyethylene.

(3) Devise compatibility test procedures for organic peroxides.

TASK 5. Develop test methods to evaluate the stress cracking of polyethylene caused by the hazardous materials stored in them.

The following subtasks are to be performed:

(1) Identify the major factors and classes of chemicals which cause stress cracking in polyethylene. 
(2) Identify and evaluate test methods used to assess stress cracking; and

(3) Develop laboratory test(s) and acceptance criteria using small size sample bottles or test coupons that can be used to evaluate the stress-crack resistance of polyethylene packagings of various sizes.

In preliminary work described in an earlier report to the DOT OHMO [1] ${ }^{1}$ subtasks $1(1), 1(2), 2(1), 3(1)$, and 5(1) were addressed. A brief summary of some of this work is presented here.

\subsection{COMPARISON OF DOT AND EUROPEAN REGULATIONS}

A review of both the US and European regulations reveals that, while in many respects the two sets of regulations are the same, there are significant differences between the two. The principal difference occurs in the area of compatibility testing. Current DOT regulations require that polyethylene packagings must be tested with each type of lading to be shipped. The European regulations allow for the use of one or more of six standard liquids. The six standard liquids are intended to evaluate three aspects of performance of the packaging, environmental stress cracking, swelling and permeation, and polymer degradation caused by oxidation. Current DOT regulations do not address specifically the subjects of environmental stress cracking and oxidative degradation. A second difference between the two sets of regulations concerns materials specifications. Current DOT regulations are solely performance oriented, whereas the European regulations contain two materials specifications in addition to performance evaluations. One specification requires that all polyethylene packagings have a density greater than $0.940 \mathrm{~g} / \mathrm{cm}^{3}$ after a heat treatment for one hour at $100^{\circ} \mathrm{C}$. The second requirement is that the Melt Flow Rate (MFR) be less than $12 \mathrm{~g} / 10 \mathrm{~min}$. This set of specifications is, presumably, intended to place some minimum requirement on the molecular weight and crystallinity of the polyethylene, minimize permeation, and at the same time satisfy the test requirements of a static compression or stacking test.

\subsection{DILUENTS USED IN THE SHIPPING OF ORGANIC PEROXIDES}

Correspondence with several of the major producers and shippers of organic peroxides indicates that organic peroxides are being shipped using a large number of different liquid diluents. Among the more common diluents being used are butylbenzyl phthalate, $\mathrm{t}-$ butanol and water, dioctyl phthalate, dimethyl phthalate and isobutyl isobutyrate, methylethyl ketone, and odorless mineral spirits (OMS). The most commonly used diluent is OMS which is comprised of a variety of liquid hydrocarbons. OMS will be the subject of considerable discussion later on in this report.

${ }^{1}$ Numbers in brackets refer to references found at the end of this report 


\subsection{PERMEATION OF ORGANIC LIQUIDS THROUGH POLYETHYLENE}

While there is, as yet, no theory which can be used to correlate the permeabilities of a large number of ladings through a given barrier, an empirical approach has been proposed for making such correlations [2]. Using a large data base, it was found possible to determine a simple correlation between measured values of mass loss from standard polyethylene bottles, certain properties of the permeant molecules, and properties of the polyethylene resin used in the bottles. This approach is known as the "Permachor" scheme.

The rate at which a molecule permeates through polyethylene depends upon various properties of the permeant such as size, shape, and polarity. Attempts to correlate permeation factors with any one property of the permeant were found to give rise to a wide scatter of the data points. The Permachor scheme is based on the observation that for the non-polar homologous series of straight chain hydrocarbons a plot of the logarithm of the permeation factor versus the number of carbon atoms in the permeant molecule was found to yield a straight line having a slope of -0.22 . Using the large data base of permeation results, a value was assigned to each of them by noting the distance they were shifted from the original line when plotted against the number of carbon atoms in each molecule. The Permachor value $(\pi)$ is derived from the amount of shift from the original line corresponding to the normal hydrocarbons. Once a Permachor value had been established for each of the various permeants, it was found that the same value which had been derived from the $21^{\circ} \mathrm{C}\left(70^{\circ} \mathrm{F}\right)$ data could be used at any other temperature and still yield a straight line relationship between the permeation factor and the Permachor number and with the same value of slope.

In our earlier report [1] it was concluded that the Permachor scheme appears feasible as a method for ranking the permeation characteristic of large numbers and classes of hazardous organic liquids. As a general rule, the smaller the Permachor number is the greater the permeation factor (permeation rate through polyethylene) will be. Within a given class of liquids the smallest molecules, those having the lowest molecular weight, will permeate most readily. Therefore, in choosing candidate materials to serve as standard liquids it is essential that the Permachor number be as small as possible in order to maximize the number of materials for which it can be substituted. The correlation between the Permachor number and other properties of organic liquids, including permeation factor, health hazard, boiling point, and flash point, as well as the determination of specific candidate materials to serve as standard liquids, will be a major goal of this report.

\subsection{A TEST FOR STRESS CRACKING}

A test for environmental stress-crack resistance (ESCR) is necessary as a means of screening both the polyethylene resin and the container design. Testing of the resin is necessary in order to determine the degree to which a particular resin is susceptible to stress cracking. Testing of the actual packaging is necessary as it may reveal areas of high residual stress or areas where relatively high stresses may result under low external loadings. A third goal of this report will be to recommend specific tests which can be used to evaluate both the polyethylene resin and the finished packaging. If a set of standard liquids is to be adopted for compatibility testing, one of the liquids should be a surfactant such as nonylphenoxy (polyethyleneoxy)ethanol. 


\section{COMPATIBILITY TESTING FOR PERMEATION AND/OR SWELLING}

\subsection{CANDIDATE MATERIALS AS STANDARD LIQUIDS}

In order to further investigate the feasibility of substituting a set of standard liquids for large classes of potential ladings and to base the choice of these liquids on the Permachor scheme, it is necessary to examine in some detail different properties of a large number of organic liquids. One source which provides information on flammable organic liquids is a publication by the National Fire Protection Association on Properties of Flammable Liquids, Gases and Volatile Solids [3]. This publication lists various properties which relate to flammability and health hazard of approximately 2000 organic compounds. In Table 2.1 we have listed in alphabetical order more than 100 of these compounds as well as several of their properties which are relevant to the present work. Included in the list, in addition to the compound itself, are the chemical structure, Permachor number, health factor, permeation factor, and flash point. The Permachor number was calculated using Table 2.3. The health factor is based on a scale of from 0 to 4,4 being the most hazardous and 0 the least hazardous. The flash point is defined as the minimum temperature at which a liquid gives off sufficient vapor to form an ignitible mixture with air near the surface of the liquid or within the vessel used. By "ignitible mixture" is meant a mixture within the flammable range (between upper and lower limits) that is capable of the propagation of flame away from the source of ignition when ignited. The compounds listed in Table 2.1 were selected on the basis that their Permachor number is less than 20 and on the scale of from 0 to 4 their health factor is no higher than 2 . There is one exception to the latter criterion, 1,1,1-trichloroethane. The flash points of these compounds vary from a temperature as low as $-39^{\circ} \mathrm{C}$ to one as high as $276^{\circ} \mathrm{C}$. Two of the compounds do not have a flash point. Permeation factor data are indicated where available. Compounds containing elements such as bromine, sulfur, and nitrogen are not included in this list.

Shown in Figure 2.1 is a plot of the flash point versus the Permachor number for the compounds listed in Table 2.1. It can be seen that there is no strong correlation between Permachor number and flash point. There is, however, some trend toward a higher flash point the higher the Permachor number is. Of interest here are any outliers which have low Permachor numbers but high flash points. These become candidate materials to serve as components of a standard liquid. Listed in Table 2.2 are 16 compounds which have a Permachor number of 13 or less. In addition to the Permachor number, included in the table are the health factor, boiling point, flash point and reactivity. The reactivity degree is based on a scale of from 0 to 4,4 being the most reactive and 0 being the least reactive. The assignment of degrees of reactivity is based upon the susceptibility of materials to release energy either by themselves or in combination with water. Fire exposure is one factor considered along with conditions of shock and pressure. Note that one compound listed in Table 2.1, n-butyl acetate, has a flash point of $22^{\circ} \mathrm{C}$. This is one of the six standard liquids specified under the current European regulations which allow for testing at a temperature of $40^{\circ} \mathrm{C}$. 
TABLE 2.1

PROPERTIES OF FLAMMABLE ORGANIC LIQUIDS

PERMACHOR HEALTH PERMATION FLASH

LIQUID STRUCTURE NUMBER $^{1}$ FACTOR

FACTOR $\left(21^{\circ} \mathrm{C}\right)^{3}$ POINT $\left({ }^{\circ} \mathrm{C}\right)^{4}$

\begin{tabular}{|c|c|c|}
\hline Acetaldehyde & $\mathrm{CH}_{3} \mathrm{CHO}$ & 14 \\
\hline Acetic acid & $\mathrm{CH}_{3} \mathrm{COOH}$ & 15.5 \\
\hline Acetic anhydride & $\left(\mathrm{CH}_{3} \mathrm{CO}\right)_{2} \mathrm{O}$ & 17.8 \\
\hline Acetone & $\mathrm{CH}_{3} \mathrm{COCH}_{3}$ & 13.8 \\
\hline Allyl Acetate & $\mathrm{CH}_{3} \mathrm{COCH}_{2} \mathrm{CH}: \mathrm{CH}_{2}$ & 13.5 \\
\hline Amyl Acetate & $\mathrm{CH}_{3} \mathrm{COOC}_{5} \mathrm{H}_{11}$ & 14 \\
\hline Amyl Alcohol & $\mathrm{CH}_{3}\left(\mathrm{CH}_{2}\right)_{3} \mathrm{CH}_{2} \mathrm{OH}$ & 19 \\
\hline Amylbenzene & $\mathrm{C}_{6} \mathrm{H}_{5} \mathrm{C}_{5} \mathrm{H}_{11}$ & 10.4 \\
\hline Amylbutyrate & $\mathrm{C}_{5} \mathrm{H}_{11} \mathrm{OOCC} 3 \mathrm{H}_{7}$ & 12.1 \\
\hline Amyl Chloride & $\mathrm{CH}_{3}\left(\mathrm{CH}_{2}\right)_{3} \mathrm{CH}_{2} \mathrm{Cl}$ & 7.2 \\
\hline Amyl Ether & $\left(\mathrm{C}_{5} \mathrm{H}_{11}\right)_{2} \mathrm{O}$ & 12.4 \\
\hline Amylphenyl Ether & $\mathrm{CH}_{3}\left(\mathrm{CH}_{2}\right)_{4} \mathrm{OC}_{6} \mathrm{H}_{5}$ & 11.8 \\
\hline Amyltoluene & $\mathrm{C}_{5} \mathrm{H}_{11} \mathrm{C}_{6} \mathrm{H}_{4} \mathrm{CH}_{3}$ & 11.4 \\
\hline Anisole & $\mathrm{C}_{6} \mathrm{H}_{5} \mathrm{OCH}_{3}$ & 7.8 \\
\hline Benzaldehyde & $\mathrm{C}_{6} \mathrm{H}_{5} \mathrm{CHO}$ & 14.4 \\
\hline Benzene & $\mathrm{C}_{6} \mathrm{H}_{6}$ & $5.4-7.6$ \\
\hline Benzylchloride & $\mathrm{C}_{6} \mathrm{H}_{5} \mathrm{CH}_{2} \mathrm{Cl}$ & 7.6 \\
\hline Bicyclohexyl & {$\left[\mathrm{CH}_{2}\left(\mathrm{CH}_{2}\right)_{4} \mathrm{CH}\right]_{2}$} & 14 \\
\hline Biphenyl & $\mathrm{C}_{6} \mathrm{H}_{5} \mathrm{C}_{6} \mathrm{H}_{5}$ & 10.8 \\
\hline n-Butyl Acetate & $\mathrm{CH}_{3} \mathrm{COOC}_{4} \mathrm{H}_{9}$ & 13 \\
\hline sec-Butyl Acetate & \multicolumn{2}{|c|}{$\mathrm{CH}_{3} \mathrm{COOCH}\left(\mathrm{CH}_{3}\right) \mathrm{C}_{2} \mathrm{H}_{5} 15$} \\
\hline Butyl Alcohol & $\mathrm{CH}_{3}\left(\mathrm{CH}_{2}\right)_{2} \mathrm{CH}_{2} \mathrm{OH}$ & 18 \\
\hline n-Butylbenzene & $\mathrm{C}_{6} \mathrm{H}_{5} \mathrm{C}_{4} \mathrm{H}_{9}$ & 9.4 \\
\hline sec-Butyl Benzene & $\mathrm{C}_{6} \mathrm{H}_{5} \mathrm{CH}\left(\mathrm{CH}_{3}\right) \mathrm{C}_{2} \mathrm{H}_{5}$ & 11.4 \\
\hline Butyl Benzoate & $\mathrm{C}_{6} \mathrm{H}_{5} \mathrm{COOC}_{4} \mathrm{H}_{9}$ & 12.5 \\
\hline Butyl Butyrate & $\mathrm{CH}_{3}\left(\mathrm{CH}_{2}\right)_{2} \mathrm{COOC}_{4} \mathrm{H}_{9}$ & 11.1 \\
\hline Butyl Chloride & $\mathrm{C}_{4} \mathrm{H}_{9} \mathrm{Cl}$ & 5.2 \\
\hline Butyl Phenyl Ether & $\mathrm{CH}_{3}\left(\mathrm{CH}_{2}\right)_{3} \mathrm{OC}_{6} \mathrm{H}_{5}$ & 10.8 \\
\hline Butyl Propionate & $\mathrm{C}_{2} \mathrm{H}_{5} \mathrm{COOC}_{4} \mathrm{H}_{9}$ & 14 \\
\hline Butyraldehyde & $\mathrm{CH}_{3}\left(\mathrm{CH}_{2}\right)_{2} \mathrm{CHO}$ & 13.5 \\
\hline Butyric Acid & $\mathrm{CH}_{3}\left(\mathrm{CH}_{2}\right)_{2} \mathrm{COOH}$ & 16 \\
\hline Camphor & $\mathrm{C}_{10} \mathrm{H}_{16} \mathrm{O}$ & 17.8 \\
\hline Chlorobenzene & $\mathrm{C}_{6} \mathrm{H}_{5} \mathrm{Cl}$ & 6.6 \\
\hline \multicolumn{3}{|l|}{ Chloroethyl } \\
\hline Acetate & $\mathrm{C}_{2} \mathrm{H}$ & 13.4 \\
\hline
\end{tabular}

$6.0 \quad-39$

$3.1 \quad 39$

$0.81 \quad 49$

$6.8 \quad-20$

22

$8.7 \quad 16$

33

66

57

13

57

85

82

52

$6.8 \quad 63$

$440 \quad-11$

67

74

113

15

22

1

31

$0.46 \quad 37$

71

52

107

53

$-9$

82

32

$10 \quad-22$

$\begin{array}{ll}4.8 & 72\end{array}$

$0.30 \quad 66$

$455 \quad 28$

54 
TABLE 2.1 (Cont'd)

PROPERTIES OF FLAMMABLE ORGANIC LIQUIDS

PERMACHOR HEALTH PERMATION FLASH

$\underline{\text { LIOUID }}$ STRUCTURE NUMBER $^{1}$ FACTOR ${ }^{2}$ FACTOR $\left(21^{\circ} \mathrm{C}\right)^{3}$

POINT $\left({ }^{\circ} \mathrm{C}\right)^{4}$

Chloro-4-Ethyl

\begin{tabular}{|c|c|c|c|c|c|}
\hline Benzene & $\mathrm{C}_{2} \mathrm{H}_{5} \mathrm{C}_{6} \mathrm{H}_{4} \mathrm{Cl}$ & 8.6 & 1 & & \\
\hline Chlorotoluene & $\mathrm{C}_{6} \mathrm{H}_{4} \mathrm{ClCH}_{3}$ & 7.6 & 2 & & \\
\hline Cumene & $\mathrm{C}_{6} \mathrm{H}_{5} \mathrm{CH}\left(\mathrm{CH}_{3}\right)_{2}$ & 10.4 & 2 & & \\
\hline Cyclohexane & $\mathrm{C}_{6} \mathrm{H}_{12}$ & 7.8 & 1 & 251 & \\
\hline Cyclohexanol & $\mathrm{C}_{6} \mathrm{H}_{5} \mathrm{OH}$ & 18 & 1 & & \\
\hline p-Cymene & $\mathrm{CH}_{3} \mathrm{C}_{6} \mathrm{H}_{4} \mathrm{CH}\left(\mathrm{CH}_{3}\right)_{2}$ & 11.4 & 2 & & \\
\hline Decane & $\mathrm{CH}_{3}\left(\mathrm{CH}_{2}\right)_{8} \mathrm{CH}_{3}$ & 10 & 0 & 71.2 & \\
\hline $\begin{array}{l}\text { Decahydro- } \\
\text { naphthalene }\end{array}$ & $\mathrm{C}_{10} \mathrm{H}_{18}$ & 12 & 0 & & \\
\hline Diamylene & $\mathrm{C}_{10} \mathrm{H}_{20}$ & 9.8 & 0 & & \\
\hline Dibutyl Ether & $\left(\mathrm{C}_{4} \mathrm{H}_{9}\right)_{2} \mathrm{O}$ & 9.4 & 2 & 85.5 & \\
\hline o-Dichlorobenzene & $\mathrm{C}_{6} \mathrm{H}_{4} \mathrm{Cl}_{2}$ & 7.8 & 2 & 155 & \\
\hline $\begin{array}{l}\text { 1,3-Dichloro- } \\
\text { butene }\end{array}$ & $\mathrm{CH}_{2} \mathrm{ClCH}: \mathrm{CClCH}_{3}$ & 6.2 & 2 & & 27 \\
\hline $\begin{array}{l}\text { Dichloropentane } \\
\text { Diethylcyclo }\end{array}$ & $\mathrm{C}_{5} \mathrm{H}_{10} \mathrm{Cl}_{2}$ & 7.4 & 2 & & \\
\hline hexane & $\mathrm{C}_{10} \mathrm{H}_{20}$ & 11 & 2 & & \\
\hline Diethyl Ketone & $\mathrm{C}_{2} \mathrm{H}_{5} \mathrm{COC}_{2} \mathrm{H}_{5}$ & 13.5 & 1 & & \\
\hline $\begin{array}{l}\text { Diisopropylbenzene } \\
\text { 1,3-Dimethyl- }\end{array}$ & {$\left[\left(\mathrm{CH}_{3}\right)_{2} \mathrm{CH}\right]_{2} \mathrm{C}_{6} \mathrm{H}_{4}$} & 15.4 & 0 & & \\
\hline cyclohexane & $\left(\mathrm{CH}_{3}\right)_{2} \mathrm{C}_{6} \mathrm{H}_{10}$ & 9 & 0 & & \\
\hline Dimethyl Decalin & $\mathrm{C}_{10} \mathrm{H}_{16}\left(\mathrm{CH}_{3}\right)_{2}$ & 14 & 0 & & \\
\hline Dioctyl Ether & $\left(\mathrm{C}_{8} \mathrm{H}_{17}\right)_{2} \mathrm{O}$ & 17 & 0 & & $>100$ \\
\hline 1,1-Diphenylethane & $\left(\mathrm{C}_{6} \mathrm{H}_{5}\right)_{2} \mathrm{CHCH}_{3}$ & 12.8 & 0 & & $>100$ \\
\hline Dipentene & $\mathrm{C}_{10} \mathrm{H}_{16}$ & 8.9 & 0 & 128 & \\
\hline Dodecane & $\mathrm{CH}_{3}\left(\mathrm{CH}_{2}\right)_{10} \mathrm{CH}_{3}$ & 11 & 0 & & \\
\hline Ethyl Acetate & $\mathrm{CH}_{3} \mathrm{COOC}_{2} \mathrm{H}_{5}$ & 12 & 1 & 16.5 & \\
\hline Ethyl Alcohol & $\mathrm{C}_{2} \mathrm{H}_{5} \mathrm{OH}$ & 18.5 & 0 & 0.7 & \\
\hline Ethylbenzene & $\mathrm{C}_{6} \mathrm{H}_{5} \mathrm{C}_{2} \mathrm{H}_{5}$ & 7.4 & 2 & & \\
\hline Ethyl Benzoate & $\mathrm{C}_{6} \mathrm{H}_{5} \mathrm{COOC}_{2} \mathrm{H}_{5}$ & 11.5 & 1 & & \\
\hline Ethyl Butyl Ether & $\mathrm{C}_{2} \mathrm{H}_{5} \mathrm{OC}_{4} \mathrm{H}_{9}$ & 7.4 & 2 & & \\
\hline Ethyl Caprylate & $\mathrm{CH}_{3}\left(\mathrm{CH}_{2}\right)_{6} \mathrm{COOC}_{2} \mathrm{H}_{5}$ & 13.1 & 2 & & \\
\hline Ethlycyclohexane & $\mathrm{C}_{2} \mathrm{H}_{5} \mathrm{C}_{6} \mathrm{H}_{11}$ & 9 & 1 & & \\
\hline Ethylenedichloride & $\mathrm{CH}_{2} \mathrm{ClCH}_{2} \mathrm{Cl}$ & 4.4 & 2 & & \\
\hline
\end{tabular}


TABLE 2.1 (Cont'd)

\section{PROPERTIES OF FLAMMABLE ORGANIC LIQUIDS}

PERMACHOR HEALTH PERMATION FLASH

$\underline{\text { LIQUID }}$

STRUCTURE NUMBER $^{1} \quad$ FACTOR $^{2} \quad{\text { FACTOR }\left(21^{\circ} \mathrm{C}\right)^{3}}^{{\text {POINT }\left({ }^{\circ} \mathrm{C}\right)^{4}}^{4}}$

Ethyl Ether

$\mathrm{C}_{2} \mathrm{H}_{5} \mathrm{OC}_{2} \mathrm{H}_{5}$

6.4

2

313

Ethyl Phenyl

Acetate

$\mathrm{C}_{6} \mathrm{H}_{5} \mathrm{CH}_{2} \mathrm{COOC}_{2} \mathrm{H}_{5} \quad 12.5$

99

Ethyl Propyl Ether

$\mathrm{C}_{2} \mathrm{H}_{5} \mathrm{OC}_{3} \mathrm{H}_{7}$

7.4

$\mathrm{CH}_{3}\left(\mathrm{CH}_{2}\right)_{9} \mathrm{CH}_{3}$

11

$<-20$

Hendecane

$\mathrm{CH}_{3} \mathrm{CH}_{2} \mathrm{CH}(\mathrm{OH}) \mathrm{C}_{4} \mathrm{H}_{9} 18$

2-Heptanol

$\mathrm{CH}_{3}\left(\mathrm{CH}_{2}\right)_{14} \mathrm{CH}_{3}$

15

Hexyl Alcohol

$\mathrm{CH}_{3}\left(\mathrm{CH}_{2}\right)_{4} \mathrm{CH}_{2} \mathrm{OH}$

17

$\mathrm{C}_{6} \mathrm{H}_{13} \mathrm{OC}_{6} \mathrm{H}_{13}$

13.4

Hexyl Ether

$\mathrm{C}_{10} \mathrm{H}_{17} \mathrm{OOCCH}_{3}$

Isobutylbenzene

Isodecalaldehyde

$\left(\mathrm{CH}_{3}\right)_{2} \mathrm{CHCH}_{2} \mathrm{C}_{6} \mathrm{H}_{5} \quad 11.4$

$\mathrm{C}_{9} \mathrm{H}_{19} \mathrm{CO}$

20

Isooctyl Alcohol

Methoxybenzene

$\mathrm{C}_{7} \mathrm{H}_{15} \mathrm{CH}_{2} \mathrm{OH}$

20

$\mathrm{C}_{6} \mathrm{H}_{5} \mathrm{OCH}_{3}$

8.8

Methyl Acetate

Methyl Alcohol

$\mathrm{CH}_{3} \mathrm{COOCH}_{3}$

12.6

$\mathrm{CH}_{3} \mathrm{OH}$

17.5

Methyl Benzoate

$\mathrm{C}_{6} \mathrm{H}_{5} \mathrm{COOCH}_{3}$

10.5

Methylcyclohexane

$\mathrm{CH}_{2}\left(\mathrm{CH}_{2}\right)_{4} \mathrm{CHCH}$

7

Methyl Ethyl

\begin{tabular}{llll}
\multicolumn{1}{l}{ Ketone } & $\mathrm{C}_{2} \mathrm{H}_{5} \mathrm{COCH}_{3}$ & 12.5 & 1 \\
Nonadecane & $\mathrm{CH}_{3}\left(\mathrm{CH}_{2}\right)_{17} \mathrm{CH}_{3}$ & 17.7 & 0 \\
Octadecane & $\mathrm{CH}_{3}\left(\mathrm{CH}_{2}\right)_{16} \mathrm{CH}_{3}$ & 16.7 & 0 \\
Octane & $\mathrm{CH}_{3}\left(\mathrm{CH}_{2}\right)_{6} \mathrm{CH}_{3}$ & 8 & 0 \\
Octyl Alcohol & $\mathrm{CH}_{3}\left(\mathrm{CH}_{2}\right)_{6} \mathrm{CH}_{2} \mathrm{OH}$ & 18 & 1 \\
$\begin{array}{l}\text { Phenethyl Alcohol } \\
\text { Phenyl Acetate }\end{array}$ & $\mathrm{C}_{6} \mathrm{H}_{5} \mathrm{CH}_{2} \mathrm{CH}_{2} \mathrm{OH}$ & 17.4 & 1 \\
$\begin{array}{l}\text { Propyl Benzene } \\
\text { n-propyl Butyrate }\end{array}$ & $\mathrm{CH}_{3} \mathrm{COOC}_{5} \mathrm{C}_{3} \mathrm{H}_{7}$ & 10.5 & 1 \\
$\begin{array}{l}\text { Tetradecane } \\
\text { 1,2,3,4-Tetra- } \\
\text { methyl Benzene }\end{array}$ & $\mathrm{C}_{3} \mathrm{H}_{7} \mathrm{COOC}_{3} \mathrm{H}_{7}$ & 8.4 & 2 \\
$\begin{array}{l}\text { Toluene } \\
\text { 1,2,4-Trichloro- } \\
\text { benzene }\end{array}$ & $\mathrm{CH}_{3}\left(\mathrm{CH}_{2}\right)_{12} \mathrm{CH}_{3} \mathrm{H}_{2}\left(\mathrm{CH}_{3}\right)_{4}$ & 13 & 0 \\
$\begin{array}{l}\text { 1,1,1-Trichloro- } \\
\text { ethane }\end{array}$ & $\mathrm{C}_{6} \mathrm{H}_{5} \mathrm{CH}_{3}$ & 9.4 & 0 \\
& $\mathrm{C}_{6} \mathrm{H}_{3} \mathrm{Cl}_{3}$ & 6.4 & 2 \\
& $\mathrm{CH}_{3} \mathrm{CCl}_{3}$ & 9 & \\
& & 5.6 &
\end{tabular}


TABLE 2.1 (Cont'd)

\section{PROPERTIES OF FLAMMABLE ORGANIC LIQUIDS}

\section{LIQUID}

$\begin{array}{lllc} & \text { PERMACHOR } & \text { HEALTH } & \text { FLASH } \\ \text { STRUCTURE } & \underline{\text { NUMBER }^{1}} & \underline{\text { FACTOR }^{2}} & {\text { POINT }\left({ }^{\circ} \mathrm{C}\right)^{4}}^{4}\end{array}$

Trichloroethylene

1,3,5-Trimethyl-

$\mathrm{ClHC}: \mathrm{CCl}_{2}$

5.4

2

none

Benzene

$\mathrm{C}_{6} \mathrm{H}_{3}\left(\mathrm{CH}_{3}\right)_{3}$

8.4

0

50

Tripropylene

Undecane

$\mathrm{C}_{9} \mathrm{H}_{18}$

8.6

24

$\mathrm{CH}_{3}\left(\mathrm{CH}_{2}\right)_{9} \mathrm{CH}_{3}$

10.2

65

Vinyl Toluene

$\mathrm{CH}_{3} \mathrm{C}_{6} \mathrm{H}_{4} \mathrm{CH}: \mathrm{CH}_{2}$

8.2

$\mathrm{C}_{6} \mathrm{H}_{4}\left(\mathrm{CH}_{3}\right)_{2}$

$5.8-7.4$

58

Xylene $[0, m, p]$

${ }^{1}$ Values determined from Table 2.1 in reference [2].

${ }^{2}$ Values obtained from document NFPA 325M, Fire Hazard Properties of Flammable Liquids, Gases, and Volatile Solids, 1984, National Fire Protection Assoc., Batterymarch Park, Quincy, MA 02269.

${ }^{3}$ Values obtained from document NFPA 325M, Fire Hazard Properties of Flammable Liquids, Gases, and Volatile Solids, 1984, National Fire Protection Assoc., Batterymarch Park, Quincy, MA 02269. 


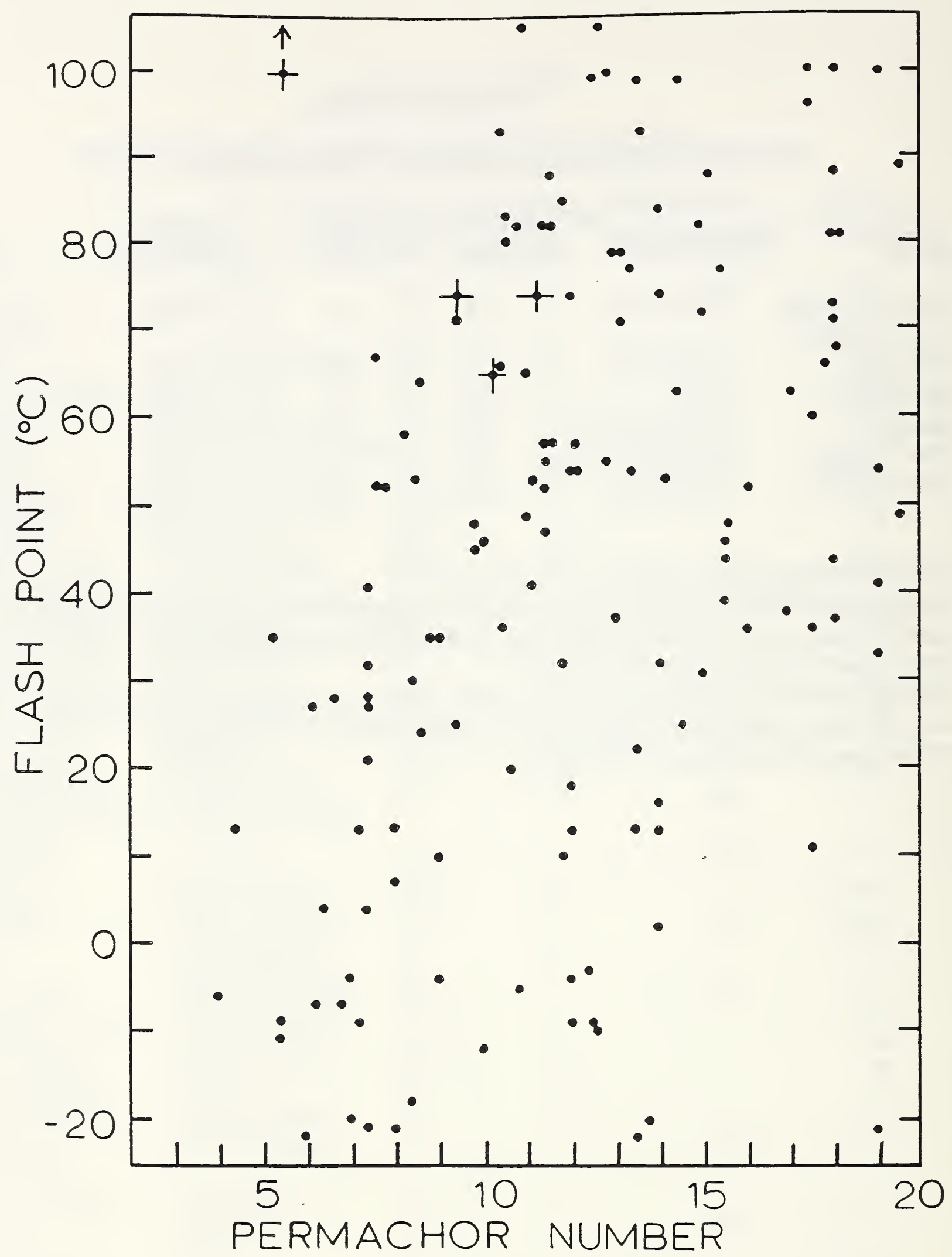

Figure 2.1

Flash point versus Permachor number for more than 100 organic liquids. 
TABLE 2.2

CANDIDATE MATERIALS FOR USE AS STANDARD LIQUIDS

PERMACHOR HEALTH BOILING FLASH

MATERIAL NUMBER FACTOR POINT $\left({ }^{\circ} \mathrm{C}\right)$ POINT $\left({ }^{\circ} \mathrm{C}\right)$ REACTIVITY

Amylbenzene

Amyltoluene

Anisole

Benzyl Chloride

n-Butyl Acetate

n-Butylbenzene

Chloro-4-Ethyl-

$$
\text { benzene }
$$

Chlorotoluene

n-Dodecane

$\mathrm{n}$-Hendecane

1,2,3,4,5-Pentamethylbenzene

1,2,3,4-Tetramethylbenzene

1,2,4-Trichlorobenzene

Trichloro-

ethylene

1,2,3-Trimethylbenzene

Vinyltoluene
10.4

11.4

7.8

7.6

13.0

9.4

8.6

7.6

11.2

10.2

10.4

9.4

9.0

5.4

8.4

8.2
185

208

154

179

127

180

184

160

216

196

232

204

213

87

175

168
66

82

52

67

22

71

64

52

74

65

93

74

105

0

none

0

53

58

0

0

0

1

0

0

0

0

0

0

0

0

53
58

0

2 
TABLE 2.3

PERMACHOR ( $\pi$ ) VALUES FOR ESTIMATING P-FACTORS

Atom or Group

Number of Carbon Atoms

$\begin{array}{llllllllll}1 & 2 & 3 & 4 & 5 & 6 & 7 & 8 & 9 & 10\end{array}$

Carbon (--c--)

$\begin{array}{llllllllll}1.0 & 1.0 & 1.0 & 1.0 & 1.0 & 1.0 & 1.0 & 1.0 & 1.0 & 1.0\end{array}$

Chlorine(--Cl)

$\begin{array}{llllllllll}1.2 & 1.2 & 1.2 & 1.2 & 1.2 & 1.2 & 1.2 & 1.2 & 1.2 & 1.2\end{array}$

Ether (--O--)

$\begin{array}{llllllllll}2.4 & 2.4 & 2.4 & 2.4 & 2.4 & 2.4 & 2.4 & 2.4 & 2.4\end{array}$

Ester (-O--)

$\begin{array}{lllllllll}9.6 & 9.6 & 8.0 & 7.0 & 7.0 & 7.0 & 3.1 & 3.1 & 3.1\end{array}$

Ketone $(\because-\mathrm{R})$

$\begin{array}{lllllllll}10.8 & 10.8 & 8.5 & 8.5 & 8.5 & 8.5 & 8.5 & 8.5 & 8.5\end{array}$

Aldehyde $(1-\mathrm{H})$

$\begin{array}{llllllllll}17.8 & 12.0 & 12.0 & 9.5 & 9.5 & 8.0 & 8.0 & 8.0 & 8.0 & 8.0\end{array}$

Anhydride ( 50 )

$\begin{array}{llllllllll}- & 15.8 & 15.8 & 18.0 & 18.0 & 18.0 & 18.0 & 18.0 & 18.0 & 18.0\end{array}$

Amide $(-\mathrm{N}-\mathrm{N}-)$

Amide (-N-

$\begin{array}{llllllllll}18.0 & 18.0 & 18.0 & 18.0 & 18.0 & 18.0 & 18.0 & 18.0 & 18.0 & 18.0\end{array}$

Amine(-- $\left.\mathrm{NH}_{2}\right)$ Aliphatic

$6.0 \quad 6.0$

6.06.

6.06.

$6.0 \quad 6.0$

Amine Aromatic

$-\quad-\quad-\quad-$

$\begin{array}{lllll}11.0 & 11.0 & 11.0 & 11.0 & 11.0\end{array}$

$\begin{array}{lllllllllll}\text { Alcohol(--OH)Aliphatic } & 16.5 & 16.5 & 15.5 & 14.0 & 14.0 & 11.0: & 11.0 & 10.0 & 10.0 & 10.0\end{array}$

Alcohol Aromatic

Acid ( $(-\mathrm{OH})$ Aliphatic

$-$

$-\quad-\quad-$

$\begin{array}{llllll}- & 13.0 & 13.0 & 13.0 & 13.0 & 13.0\end{array}$

$\begin{array}{llllllllll}18.0 & 13.5 & 13.5 & 11.0 & 11.0 & 11.0 & 11.0 & 11.0 & 11.0 & 11.0\end{array}$

Acid Aromatic

Phenyl Benzene

$\begin{array}{lllll}14.0 & 14.0 & 14.0 & 14.0 & 14.0\end{array}$

Mono, ortho, meta Para

Iso subst. \& Side branching

5.4 below $80^{\circ} \mathrm{F}, \quad 7.6$ above

$\begin{array}{lllll}5.4 & 5.4 & 5.4 & 5.4 & 5.4\end{array}$

3.8 below $80^{\circ} \mathrm{F}, \quad 5.4$ above Add 2.0

Double Bond Between Carbons

Subtract 0.2

Alicyclic $(\bigcirc \bigcirc \square \Delta)$

Add 1.0 below $80^{\circ} \mathrm{F}, 2.0$ above $80^{\circ} \mathrm{F}$ 
Note that only two of the straight chain hydrocarbons are included in Table 2.2. These are the two lowest molecular weight normal paraffins which satisfy the European requirements for the standard liquid labelled "mixture of hydrocarbons (white spirit)". For example, decane has a flash point of $46^{\circ} \mathrm{C}$ which is $15^{\circ} \mathrm{C}$ lower than the minimum allowable value under the current European regulations. For the n-paraffins longer than dodecane the permeation factor decreases rapidly with increased chain length, as was demonstrated in our earlier report [1]. Three of the compounds (1,2,3,4-tetramethylbenzene, 1,2,4-trichloro benzene, and trichloroethylene) have small Permachor numbers but relatively high boiling points and flash points. Trichloroethylene has the smallest Permachor number and is reported to have no flash point but a health factor of 2 and a boiling point of $87^{\circ} \mathrm{C}$. Perhaps the most promising candidate of the aromatic compounds listed in Table 2.2 is $1,2,3,4-$ tetramethylbenzene which has a Permachor number of 9.4 , a health factor of 0 , a boiling point of $204^{\circ} \mathrm{C}$ and a flash point of $74^{\circ} \mathrm{C}$. The flash point of this material is seemingly high enough to allow it to be used in tests conducted at a temperature as high as $60^{\circ} \mathrm{C}$. Of the straight chain hydrocarbons, dodecane would be suitable for testing at all three test temperatures.

\subsection{EXPERIMENTAL WORK IN SUPPORT OF THE PERMACHOR SCHEME}

Having determined a set of candidate materials to be used as standard liquids, experimental work was done to further examine the validity of the Permachor scheme discussed earlier. Permeation factors were determined for twenty-two different organic liquids including the normal paraffins, normal butyl acetate, and acetic acid. Both normal butyl acetate and acetic acid are standard liquids used in European tests. The permeation measurements were done according to ASTM D 2684 - 89, Standard Test Method for Permeability of Thermoplastic Containers to Packaged Reagents of Proprietary Products, Procedure A [4]. Tests were conducted at three different temperatures, 23,50 and $60^{\circ} \mathrm{C}$. The test specimen for Procedure A was the $120 \mathrm{~mL}$ (approximately 4-oz) cylindrical bottle design as specified in Figure 1 of ASTM D 2684. This type of bottle has a nominal external surface area of $154 \mathrm{~cm}^{2}\left(23.8 \mathrm{in}^{2}\right)$. The bottles were manufactured from a commercial polyethylene resin of the type used in the manufacture of large blow-molded containers for hazardous materials transportation (density $=0.950 \mathrm{~g} / \mathrm{cm}^{3}$ ). The average wall thickness of the bottles was $0.083 \mathrm{~cm}$ as determined from measurements made on three different bottles. The closures were phenolic screw-type caps with an inner liner which was an aluminum foil and paper laminate. This type of cap was found in earlier work [5] to provide a good seal. Because of a limited supply of some of the reagents, most of the bottles were filled to about three fourths full rather than nominal capacity. For each test temperature and reagent three bottles were used. The Permeation Factor $P_{t}=R T / A$, where $P_{t}$ is in metric units $g$ $\mathrm{cm} /$ day $\cdot \mathrm{m}^{2}$. $R$ is the rate of average weight change, $\mathrm{g} /$ day, $T$ is the average bottle thickness, $\mathrm{cm}$, and $\mathrm{A}$ is the nominal bottle surface area, $\mathrm{m}^{2}$.

Shown in Table 2.4 are permeation data obtained on the twenty-two organic liquids at three different temperatures. The compounds are listed in the order of increasing Permachor number as calculated using the scheme in Table 2.3. The numbers not in parentheses are in metric units and those in parentheses are given in the set of mixed units used earlier by 
Salame [2]. In Figures 2.2-2.4 the permeation factor is plotted versus the Permachor number for each of the three temperatures. The straight lines represent a linear regression fit of the data points. The slope, intercept, and coefficient of correlation are shown on each figure.

\section{TABLE 2.4}

\section{PERMEATION FACTORS FOR TWENTY-TWO ORGANIC LIOUIDS}

\begin{tabular}{|c|c|c|c|c|}
\hline \multirow{2}{*}{$\begin{array}{l}\text { Chemical } \\
\text { Compound }\end{array}$} & \multirow{2}{*}{$\begin{array}{l}\text { Permachor } \\
\text { Number }\end{array}$} & \multicolumn{3}{|c|}{ Permeation Factors ${ }^{1}$} \\
\hline & & $\underline{23^{\circ} \mathrm{C}}$ & $\underline{50^{\circ} \mathrm{C}}$ & $60^{\circ} \mathrm{C}$ \\
\hline $\mathrm{n}$-Hexane & 6.0 & $1.69(43.0)$ & $12.97(329.0)$ & $25.39(644.0)$ \\
\hline Toluene & 6.4 & $2.99(75.8)$ & $20.05(508.9)$ & $40.56(1029)$ \\
\hline $\mathrm{n}$-Heptane & 7.0 & $1.38(35.0)$ & $8.72(221.0)$ & $15.79(401.0)$ \\
\hline Xylenes & 7.4 & $1.83(46.4)$ & $13.20(334.0)$ & $21.80(553.0)$ \\
\hline Octane & 8.0 & $1.01(25.7)$ & $6.30(160.0)$ & $12.3(313.0)$ \\
\hline $\begin{array}{l}\text { Trichloro- } \\
\text { benzene }\end{array}$ & 9.0 & $0.64(16.1)$ & $7.24(184.0)$ & $10.96(278.0)$ \\
\hline $\begin{array}{l}\text { 1,2,3,4-Tetra- } \\
\text { methylbenzene }\end{array}$ & 9.4 & $0.30(7.59)$ & $3.91(99.3)$ & $6.73(171.0)$ \\
\hline Trimethyl pentane & 10.0 & $0.12(3.0)$ & $1.81(46.0)$ & 3.83 (97.4) \\
\hline n-Decane & 10.0 & $0.46(11.6)$ & $3.63(92.1)$ & $6.54(166.1)$ \\
\hline n-Undecane & 10.2 & $0.36(9.04)$ & $2.65(67.3)$ & $4.57(116.0)$ \\
\hline n-Dodecane & 11.0 & $0.20(5.05)$ & $2.20(55.9)$ & $3.47(88.1)$ \\
\hline $\begin{array}{l}\text { n-Tetradecane } \\
\text { n- Butyl- }\end{array}$ & 13.0 & $0.14(3.63)$ & $1.32(33.5)$ & $2.33(59.2)$ \\
\hline Acetate & 13.0 & $0.13(3.21)$ & $1.62(41.0)$ & $3.52(89.2)$ \\
\hline Acetone & 13.8 & $0.10(2.53)$ & $0.77(19.5)$ & $1.81(45.9)$ \\
\hline n-Pentadecane & 14.0 & $0.10(2.53)$ & $1.08(27.3)$ & $1.98(50.2)$ \\
\hline n-hexadecane & 15.0 & $0.024(0.61)$ & $0.95(24.2)$ & $1.69(42.9)$ \\
\hline t-butyl acetate & 15.0 & $0.02(0.50)$ & $0.44(11.2)$ & $1.19(30.2)$ \\
\hline $\begin{array}{l}\text { Acetic Acid } \\
\text { Methyl }\end{array}$ & 15.5 & $0.023(0.58)$ & $0.29(7.42)$ & $0.61(15.5)$ \\
\hline $\begin{array}{l}\text { Alcohol } \\
\text { n-Butyl }\end{array}$ & 17.5 & $0.043(1.08)$ & $0.33(8.34)$ & $0.64(16.3)$ \\
\hline Alcohol & 18.0 & $0.0034(0.086)$ & $0.080(2.03)$ & $0.22(5.49)$ \\
\hline $\begin{array}{l}\text { Ethyl Alcohol } \\
\text { n-Propyl }\end{array}$ & 18.5 & $0.0183(0.465)$ & $0.142(3.60)$ & $0.32(3.60)$ \\
\hline Alcohol & 18.5 & $0.0092(0.233)$ & $0.103(2.61)$ & $0.21(5.28)$ \\
\hline
\end{tabular}

${ }^{1} \mathrm{~g} \cdot \mathrm{cm} /$ day $\cdot \mathrm{m}^{2}\left(\mathrm{~g} \cdot \mathrm{mil} /\right.$ day $\left.\cdot 100 \mathrm{in}^{2}\right)$ 


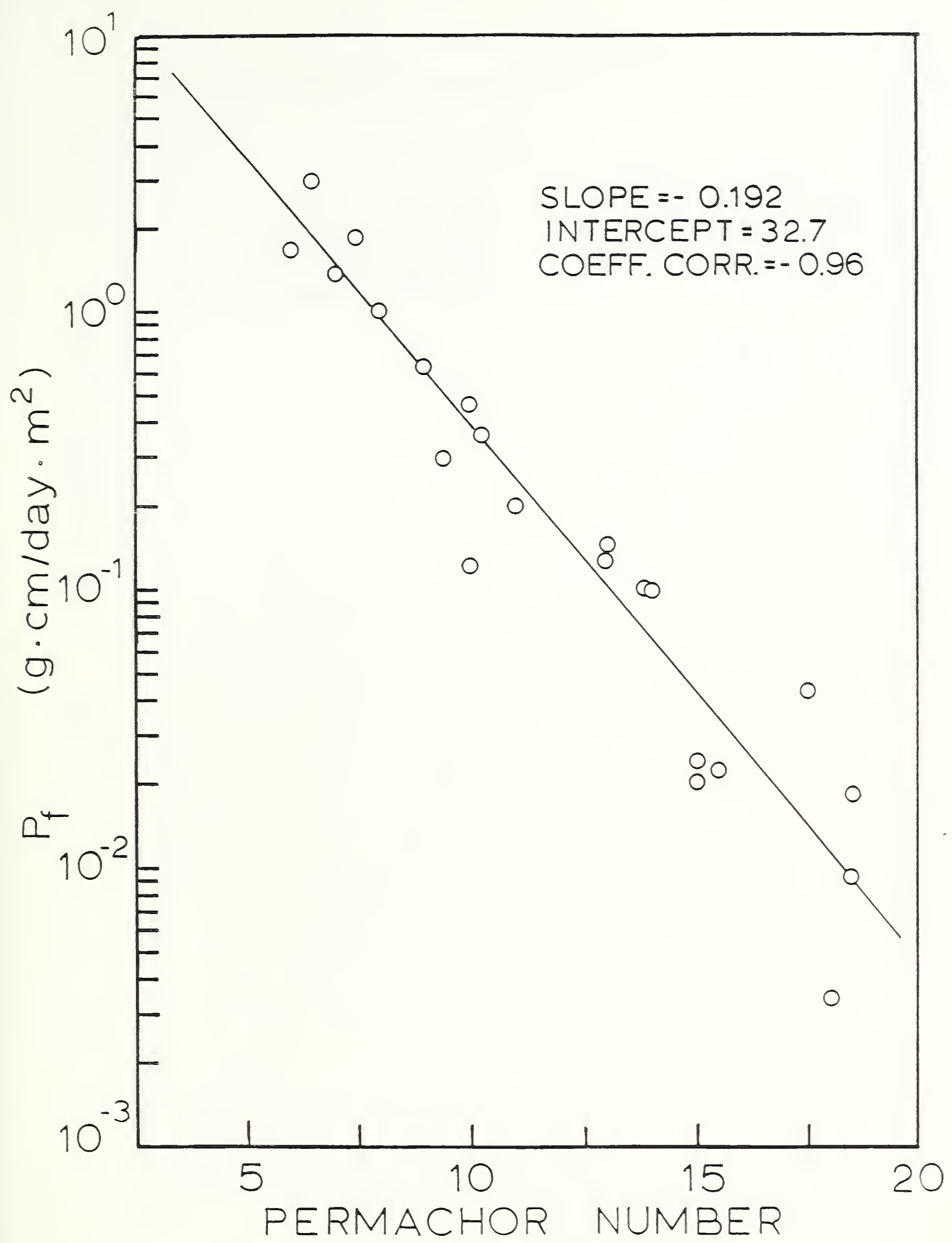

Figure 2.2 Permeation factor versus Permachor number at $23^{\circ} \mathrm{C}$. 


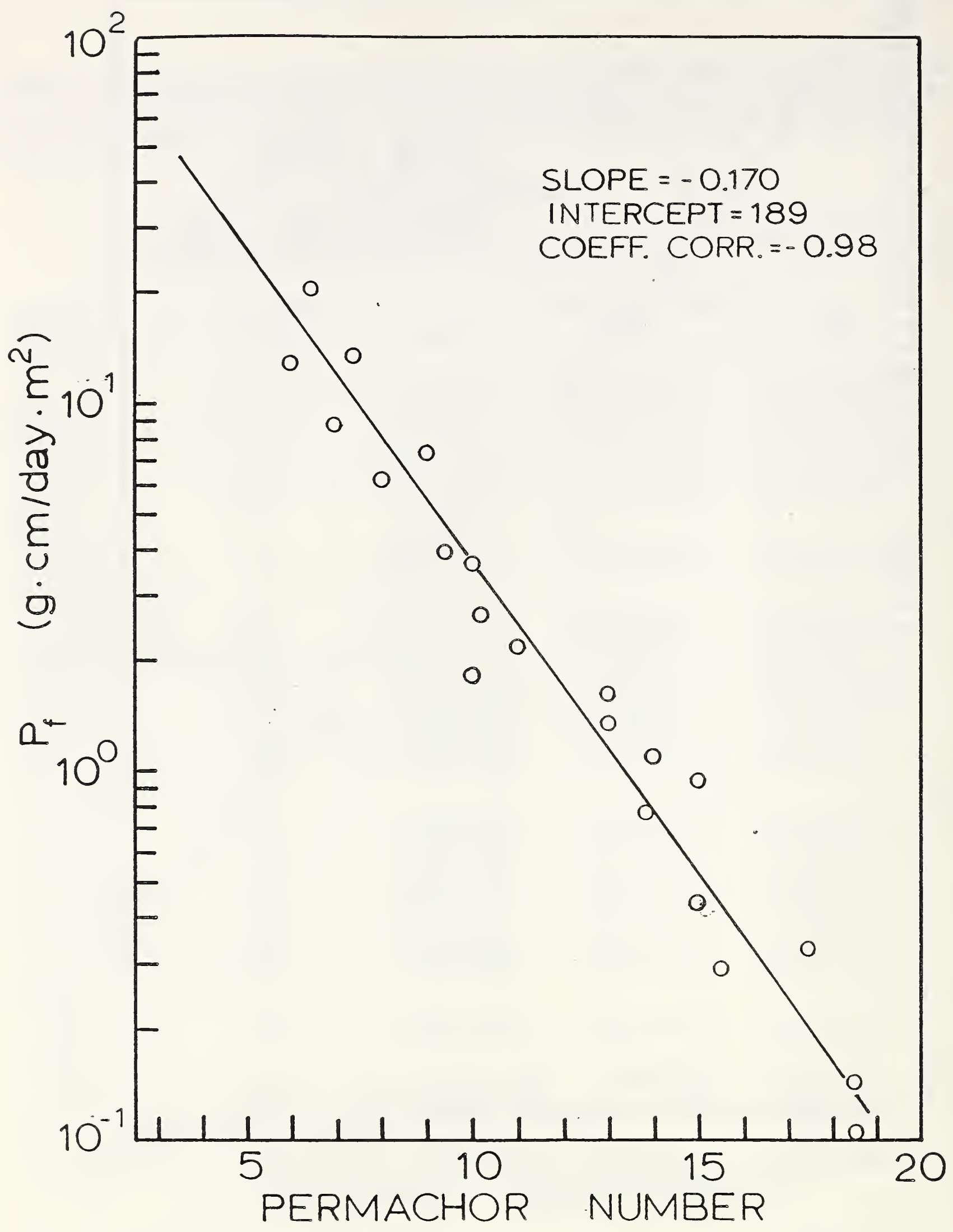

Figure 2.3

Permeation factor versus Permachor number at $50^{\circ} \mathrm{C}$. 


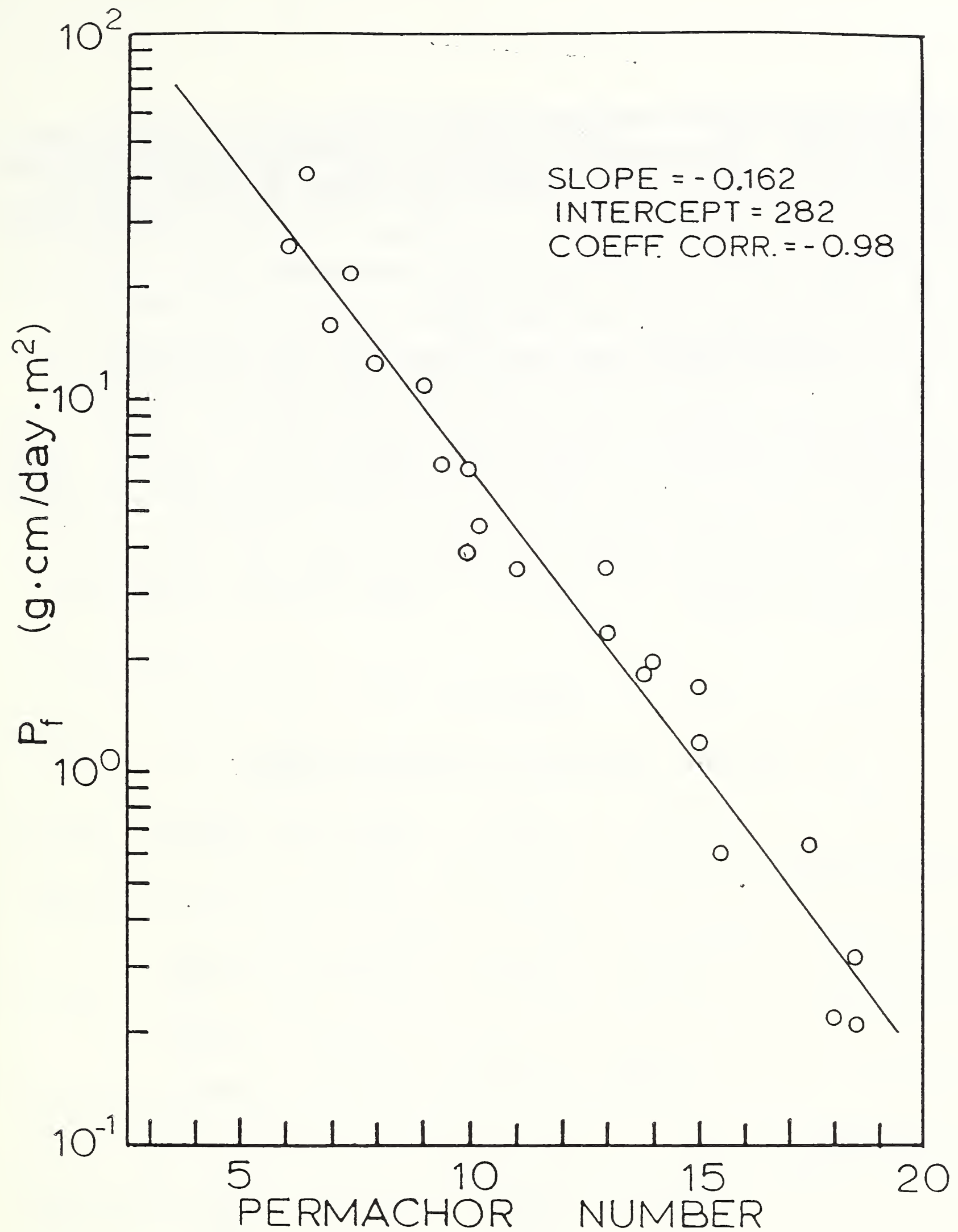

Figure 2.4

Permeation factor versus Permachor number at $60^{\circ} \mathrm{C}$. 
Qualitatively, the three sets of results obtained here show the same behavior as that obtained by Salame. However, quantitatively there are three differences that bear mention. In the earlier work it was found that the magnitude of the slope of the straight line fit was independent of the temperature. That result is not found to be the case in the present work. For the polyethylene used in this work the slope varied from -0.192 at $23^{\circ} \mathrm{C}$ to -0.162 at $60^{\circ} \mathrm{C}$. Moreover, the slope at all three temperatures is somewhat less than the value of -0.22 found in the earlier work. The third difference is that the magnitude of the permeation factors determined by Salame are considerably larger than those found in the present work; on average they are about a factor of ten larger. At this point it is not known whether the differences observed between the two sets of results arise from differences in the types of polyethylenes used or from other physical factors including the experimental technique.

In addition to the twenty-two chemical reagents discussed above, we have also investigated several chemical mixtures which fall under the general classification of "mineral spirits". Mineral spirits are normally petroleum distillates which are comprised of a large variety of normal and branched saturated hydrocarbons as well as a small amount of aromatic compounds. Four types of mineral spirits are specified in ASTM D 235 - 87, Standard Specification for Mineral Spirits [6]. Some relevant characteristics of the four types are provided in Table 2.5 below.

TABLE 2.5

PHYSICAL PROPERTIES OF MINERAL SPIRITS

\begin{tabular}{|c|c|c|c|c|}
\hline & Type I & Type II & Type III & Type IV \\
\hline Commercial Reference & regular & $\begin{array}{l}\text { high flash } \\
\text { point }\end{array}$ & odorless & low dry point \\
\hline $\begin{array}{l}\text { Flash Point }{ }^{\circ} \mathrm{C}\left({ }^{\circ} \mathrm{F}\right) \\
\text { Initial Boiling }\end{array}$ & $38(100)$ & $60(140)$ & $38(100)$ & $38(100)$ \\
\hline Point, $\min { }^{\circ} \mathrm{C}\left({ }^{\circ} \mathrm{F}\right)$ & $149(300)$ & $177(350)$ & $149(300)$ & $149(300)$ \\
\hline Dry Point, $\max ^{1}$ & $213(415)$ & $213(415)$ & $213(415)$ & $185(365)$ \\
\hline $\begin{array}{l}\text { Apparent Specific } \\
\text { Gravity } 15.6^{\circ} \mathrm{C}\left(60^{\circ} \mathrm{F}\right)\end{array}$ & & & & \\
\hline $\begin{array}{l}\min \\
\max \end{array}$ & $\begin{array}{l}0.754 \\
0.820\end{array}$ & $\begin{array}{l}0.768 \\
0.820\end{array}$ & 0.775 & $\begin{array}{l}0.754 \\
0.800\end{array}$ \\
\hline
\end{tabular}

${ }^{1}$ The dry point is defined as the thermometer reading at the instant the last drop of liquid evaporates from the lowest point of the flask during distillation. 
Permeation measurements were carried out on several different commercial brands of mineral spirits using the same ASTM procedures and bottle type described earlier. Commercial products were obtained from three different manufacturers. The results are presented in Table 2.6 below.

\section{TABLE 2.6}

\section{PERMEATION DATA FOR VARIOUS TYPES OF MINERAL SPIRITS}

Type of Initial

Mineral Boiling Flash Density Permachor Permeation Factor $\left(\mathrm{g} \cdot \mathrm{cm} /\right.$ day $\left.\cdot \mathrm{m}^{2}\right)$

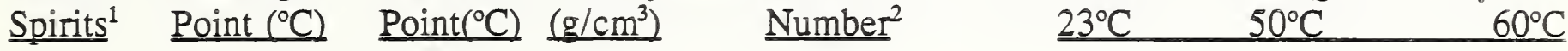

$\begin{array}{lccccccc}\text { III (1) } & 179 & 52 & 0.76 & 14.8 & <0.01 & 0.51 & 1.19 \\ \text { II (1) } & 187 & 62 & 0.79 & 11.6 & 0.15 & 2.01 & 3.95 \\ \text { I (2) } & 160 & 41 & 0.75 & 13.4 & <0.01 & 0.90 & 1.98 \\ \text { II (2) } & 181 & 57 & 0.76 & 14.6 & <0.01 & 0.55 & 1.28 \\ \text { II (2) } & 223 & 89 & 0.78 & 16.8 & <0.01 & 0.22 & 0.60 \\ \text { II (2) } & 233 & 99 & 0.79 & 17.2 & <0.01 & 0.18 & 0.53 \\ \text { III (3) } & 174 & 49 & 0.77 & 14.8 & <0.01 & 0.52 & 1.23 \\ \text { II (3) } & 185 & 60 & 0.77 & 14.9 & <0.01 & 0.48 & 1.20 \\ \text { II (3) } & 223 & 90 & 0.79 & 17.0 & -- & 0.21 & 0.52\end{array}$

${ }^{1}$ Numbers in parentheses refer to the manufacturer identification.

Roman Numerals designate the type of mineral spirits according to ASTM D 235.

${ }^{2}$ The Permachor numbers represent an average for the mixture and were estimated from Figures 2.2-2.4.

For manufacturers (2) and (3), the trend is, the higher the flash point the lower the permeation factor (larger Permachor number). An important exception is manufacturer (1) for which the reverse is true. In view of the trend for manufacturers (2) and (3), the results for the products from manufacturer (1) are somewhat surprising. To insure that the two 
products were not mislabelled, the densities of the two liquids were measured and were found to be in the proper order. In order to achieve a higher flash point, the procedure generally is to mix in a greater amount of branched paraffinic species. For example, in Table 2.4 octane has a permeation factor greater than three times that for trimethylpentane which has the same number of carbon atoms in the molecule. A second example is normal butyl acetate which also has a permeation factor about three times that of tertbutyl acetate. It would appear that a detailed chemical analysis to determine the various molecular species in each type of mineral spirits would be of value.

The results found here for the various types of mineral spirits would appear to have some interesting consequences with respect to their use as a standard liquid. For the nine different products examined in this study, the permeation factor varied by as much as a factor of eight. Most of the liquids in Table 2.6 having a flash point above $60^{\circ} \mathrm{C}$ would not appear suitable as a standard liquid because their permeation factors are too small. The one exception is the product labelled II (1) which has an average Permachor number of 11.6. Even this value is somewhat larger than one would like. Some advantage may be gained by the addition of aromatic compounds as is done in the European regulations. However, even most aromatic compound having nine or more carbon atoms in the molecule will not have a Permachor number substantially lower than 11.6. Of the nine types of mineral spirits, only the one labelled II(1) meets all three specifications required by the European regulations. The conclusion to be drawn at this point is that, if one or more types of mineral spirits is to be used as a standard liquid, their composition should be carefully controlled. It should be pointed out that these same manufacturers may have other formulations which were not tested that do satisfy all three specifications.

\section{TEST METHODS TO EVALUATE THE STRESS CRACKING OF POLYETHYLENE}

It was pointed out in our earlier report [1] that under certain conditions of stress, and in the presence of certain environments, polyethylene packagings may exhibit mechanical failure by cracking at a stress appreciably less than would cause cracking in the absence of such an environment. Classes of compounds which are particularly aggressive toward polyethylene are oils, soaps, wetting agents and detergents. These classes of chemical agents do not necessarily permeate through the polyethylene and appear on the outside of the container unless a crack penetrates completely through the wall of the container. Even though liquid may not appear on the outside wall of the container the mechanical integrity of the packaging can be severely compromised due to the formation of many small cracks within the wall of the packaging.

Polyethylenes may vary greatly in their resistance to stress cracking depending upon such factors as molecular weight, molecular weight distribution, branch content and distribution of branches within the different molecular weight species. Therefore, a test for environmental stress-crack resistance (ESCR) is important both as a means for screening different polyethylene resins and for testing a new container design. Testing of the resin is of particular interest to the container manufacturer as a means of determining the degree to which a particular resin is susceptible to ESCR. Two standard test methods are currently in 
widespread use by industry as a means determining the ESCR of polyethylene resins. A brief description of the two methods is provided below.

ASTM D 1693-70 (Reapproved 1988) Standard Test Method for Environmental Stress-Cracking of Ethylene Plastics [4] involves the use of test coupons in the form of strips prepared from compression molded sheets of the polymer. A controlled imperfection, in the form of a surface notch, is introduced on one side of each strip using a sharp blade such as a razor blade. Each strip is then bent into the shape of a $U$ and placed in a test tube containing a surface active agent maintained at $50^{\circ} \mathrm{C}$. The reagent most commonly used in this test is nonylphenoxy poly(ethyleneoxy)ethanol, either at full strength or in a mixture with distilled water. A minimum of ten specimens is tested. The specimens are inspected at periodic intervals for the appearance of visible cracks. The occurrence of a crack constitutes failure of the specimen. In this test method emphasis is placed on the $50 \%$ failure time, although other failure times may be of just as much interest and relevance, for example the initial failure time $\left(\mathrm{F}_{\mathrm{i}}\right)$ and the $100 \%$ failure time $\left(\mathrm{F}_{100}\right)$.

The second test, ASTM D 2561-70 (Reapproved 1989) Standard Test Method for Environmental Stress-Crack Resistance of Blow-Molded Polyethylene Containers [4], can be used either to screen polyethylene resins or to test a finished packaging. This test contains three separate procedures which address different applications.

Procedure A is recommended for determining the effect of container design on stresscrack resistance. This procedure consist of exposing any filled, sealed, blow-molded container to the action of a potential stress-cracking agent within the container, at an elevated temperature $\left(60^{\circ} \mathrm{C}\right)$. The time to failure is reported.

Procedure $B$ is designed for testing containers made from Type III polyethylene as defined in ASTM D 1248 [5]. This procedure is recommended for containers made from Type III polyethylene only. Procedure B consists of exposing a partially filled, sealed, blowmolded standard container to the action of a polyoxyethylated nonylphenol, a stress-cracking agent, within the container, as well as to the action of this agent as an external environment, at an elevated temperature $\left(60^{\circ} \mathrm{C}\right)$. Again, the time to failure is recorded.

Procedure $\mathrm{C}$ is similar to Procedure B except that the container is not exposed to the agent as an external environment and a constant elevated internal pressure is applied ( 34.5 $\mathrm{kPa}$ ).

Both Procedures $\mathrm{B}$ and $\mathrm{C}$ involve the use of a standard $473 \mathrm{~mL}(16 \mathrm{oz})$ blow-molded bottle of the design specified under 9.2.1 of ASTM D 2561.

If an ESCR test is to be considered as a requirement for qualifying a polyethylene resin or container design, then criteria must be established which can be used as a basis for setting minimum acceptable limits on the failure times. Such criteria would presumably be based on one or more of the $F_{i}, F_{50}$, or $F_{100}$ failure times as determined from an ESCR test of the type described above. In establishing such criteria it is important to have as large a data base of test results as possible covering the different types of polyethylene used in the packaging of hazardous materials. An industry wide consensus as to what constitutes a minimum acceptable failure time for different types of polyethylene would be useful in this regard. 


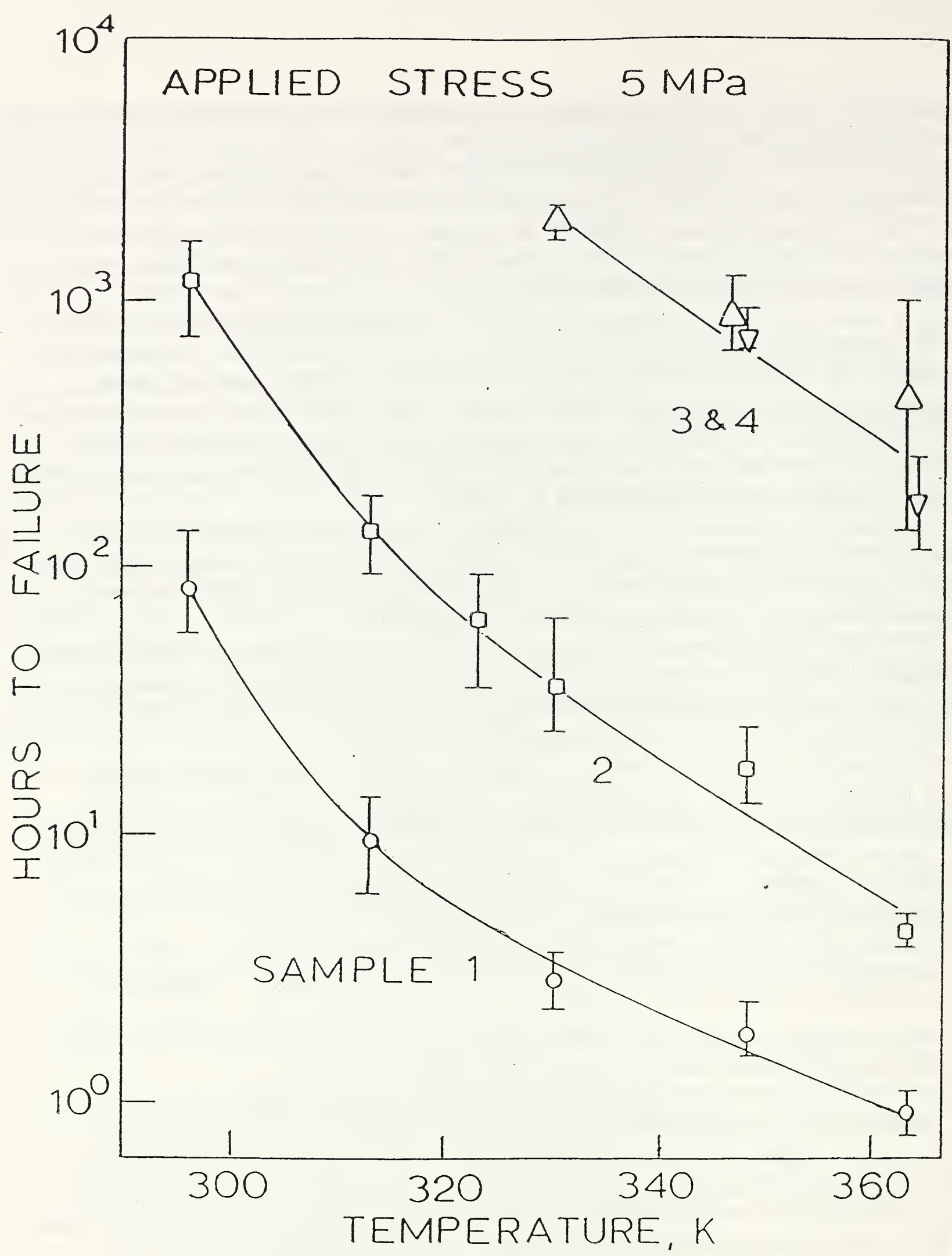

Figure 3.1

Hours to failure versus temperature from ESCR tests on four types of polyethylene. 


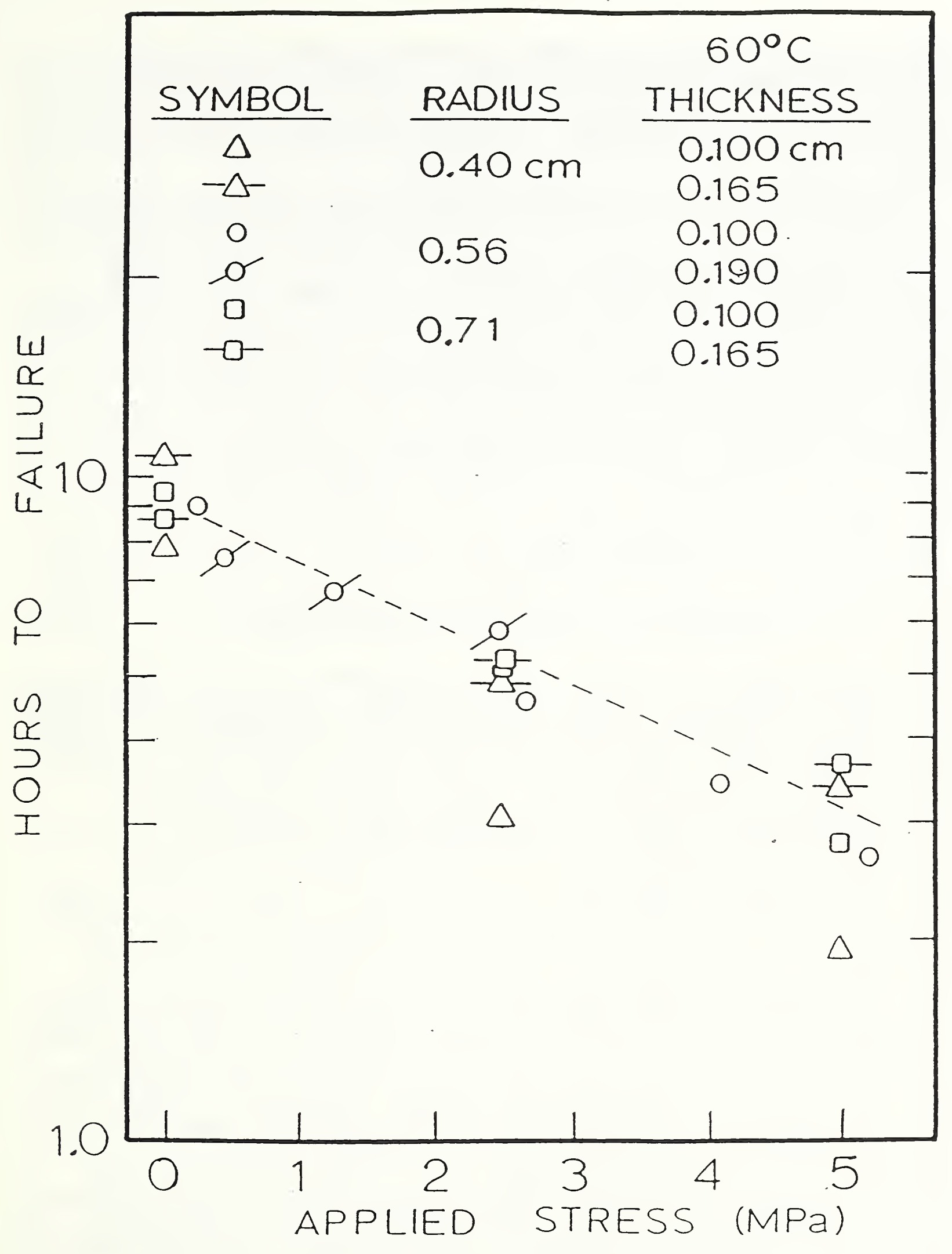

Figure 3.2

Hours to failure versus applied stress for specimens having varied thickness and bend radius. 
For the purpose of qualifying packagings, an alternative approach to the tests described above is the one described in the European test methods. For high molecular weight polyethylene drums, the environmental stress-crack resistance is verified by using the so-called Pin Impression Method ISO 4600. This method is described in some detail later on in this report.

As a demonstration of the extent to which the failure time depends upon temperature, we show in Figure 3.1 the results of ESCR tests conducted on four different polyethylenes having weight average molecular weights ranging from $10^{5}$ to $4 \times 10^{6}$. The data were obtained using a special ESCR test method developed in our laboratory [6], thus no attempt should be made to compare these results with results obtained using either of the two ASTM tests described earlier. If sample 2 is used as an example, it can be seen that by raising the temperature from $40^{\circ} \mathrm{C}$ to $60^{\circ} \mathrm{C}$ there is a decrease in the failure time of approximately a factor of four, or from $40^{\circ} \mathrm{C}$ to $50^{\circ} \mathrm{C}$ a factor of about two. It should be observed that the test results shown in Figure 3.1 were obtained using an applied external stress of $5 \mathrm{MPa}$. The application of an externally applied stress is also an important factor in accelerating failure. An example of this behavior is shown in Figure 3.2 where the time to failure is plotted versus the applied stress for specimens of the polyethylene identified in Figure 3.1 as sample 1. By increasing the applied stress from 0 to $5 \mathrm{MPa}$ there is, on average, a decrease in the failure time of about a factor of three. We note that procedures A and B in ASTM D 2561 do not require the application of an added stress, but do take advantage of an elevated temperature.

One possible means of introducing stress as part of the test would be to combine a test such as ASTM D 2561 with a stacking or static compression test. Marginal 3555 of the European regulations provides that the stacking test be carried out with a standard liquid, for the purposes of ESCR testing a wetting agent. However the stacking test used in Europe is carried out for 28 days at a temperature of $40^{\circ} \mathrm{C}$. Where feasible, there would be an advantage in conducting this test at $60^{\circ} \mathrm{C}$, the same temperature used in ASTM D 2561. The static compression or stacking test load would have to be adjusted accordingly to compensate for the increase in temperature.

In an effort to examine more closely the two ASTM tests for ESCR described above, a series of tests was done using both test methods. Two commercial polyethylenes of the type used in large blow-molded plastic drums were obtained from one resin manufacturer. The two resins are designated as type A and type B. The type A resin is the same polymer from which the standard bottles for the permeation measurements were manufactured. Both polyethylenes are classified as Type III resins as defined in ASTM D 1248-84 Standard Specification for Polyethylene Plastics Molding and Extrusion Materials [7]. The ESCR $\mathrm{F}_{50}$ values for the two resins under Condition A or B of ASTM D 1693 are quoted by the manufacturer to be 800 hours for the type A resin and $>1000$ hours for the type B resin.

Specimens to be tested according to ASTM D 1693, Condition B, (bent strip test) were prepared in accordance with ASTM D 1928-80 Standard Method for Preparation of Compression-Molded Polyethylene Test Sheets and Test Specimens [4]. Condition B was chosen rather than Condition $A$ on a basis of the availability of molding equipment. Conditions A and B differ only in the specimen thickness and notch depth. Ten specimens of each type of polyethylene were cut from the compression-molded sheets using a die having a 
width of one half inch and a length of one and a half inches. The specimens were then nicked and bent in accordance with the procedures specified in ASTM D 1693. For the first set of tests a time of 35 seconds was allowed to completely bend the specimens as recommended in the ASTM test. Each set of ten specimens was placed in a test tube filled with a ten percent solution of nonylphenoxypolyethyleneoxyethanol in distilled water. The test tubes were placed in a water bath controlled at $50.0+1-0.1^{\circ} \mathrm{C}$ and the specimen examined daily until all ten had failed.

The results for the first set of tests (set 1 ) are presented in Table 3.1. In view of the rather surprising results, two more sets of ten specimens of each type of resin were also tested. The results of these two sets of tests are also given in Table 3.1 and are identified as sets 2 and 3. The only difference in procedures for the latter two sets of tests was that in set 2 a time of one minute was allowed to bend the specimens and a time of two minutes was used in set 3. From Table 3.1 it can be seen that the results are virtually the same for all three sets. The $F_{50}$ failure times from all three sets of tests are, on average, less than one fourth the values quoted by the resin manufacturer.

\section{TABLE 3.1}

\section{ESCR TEST RESULTS USING ASTM D 1693}

\begin{tabular}{|c|c|c|c|c|c|c|}
\hline \multirow{2}{*}{$\begin{array}{l}\text { Failure Time } \\
\text { (hours) }\end{array}$} & \multicolumn{4}{|c|}{ Resin A } & \multicolumn{2}{|c|}{ Resin B } \\
\hline & set 1 & set 2 & set 3 & set 1 & set 2 & set 3 \\
\hline$F_{i}$ & 160 & 144 & 143 & 139 & 144 & 96 \\
\hline $\mathrm{F}_{50}$ & 220 & 210 & 200 & 180 & 150 & 134 \\
\hline$F_{100}$ & 351 & 240 & 311 & 305 & 167 & 192 \\
\hline
\end{tabular}

At this point we have no explanation as to why the test results obtained here are so different from the values quoted by the resin manufacturer. All three sets of results shown in Table 3.1 appear to be quite consistent with one another. At each step, the procedures were checked carefully and the nicking blade examined for possible flaws. Varying the time of bending by a factor of three appears to have had little, if any, effect on the results.

For the second test, ASTM D 2561, standard bottles of both resins A and B were obtained from the same resin manufacturer. This bottle is a $473 \mathrm{~mL}(16 \mathrm{oz})$ cylindrical blow-molded bottle weighing approximately $20 \mathrm{~g}$. Due to space limitations only ten bottles of each type were tested rather than fifteen as specified in the ASTM test. The bottles were tested according to procedure A. Each bottle was filled to two thirds capacity, the closure applied, and the bottle placed inside a clear plastic bag sealed with a rubber band. They were then set vertically in trays and placed in an oven maintained at $60+/-0.50 \mathrm{C}$. The 
bottles were examined daily for the first month, then weekly thereafter. After 8000 hours under test, none of the bottles had failed.

\section{POLYETHYLENE COMPATIBILITY WITH ORGANIC PEROXIDES}

Organic peroxides are carbon based compounds characterized by the presence of one or more peroxy linkages, -O-O-, within the molecule where $\mathrm{O}$ is oxygen. They can be considered derivatives of hydrogen peroxide, $\mathrm{H}-\mathrm{O}-\mathrm{O}-\mathrm{H}$, in which one or both of the hydrogen atoms, $\mathrm{H}$, have been replaced with an organic moiety. Because of the relative instability of the $-\mathrm{O}-\mathrm{O}$ - bond $(\Delta \mathrm{H}=-125.6$ to $-184.2 \mathrm{~kJ} / \mathrm{mol})$ [9], decomposition occurs by thermal, photolytic, transition metal, or organo-metallic activation to give rise to the formation of organo-oxy radicals.

$$
\mathrm{ROOR}\left(\Delta, h v, \rightarrow^{\text {catalyst })} \mathrm{RO} \bullet+\bullet \mathrm{OR}\right.
$$

Depending on the chemical nature of the dissociated peroxide, further homolysis yielding more stable free radicals can ensue. The stability, and therefore reactivity, of the variously formed free radicals are highly structure dependent. Free radical lifetimes are generally very short, eg, $t_{1 / 2}<10^{-3} \mathrm{sec}[10]$.

This section will summarize efforts completed to date concerning the compatibility of plastic or polyethylene containers with organic peroxides. This work has the purpose of using organic peroxides as a basis for developing compatibility test procedures for liquids that are unstable with polyethylene packaging at $21^{\circ} \mathrm{C}$. These may include organic peroxides and other free radical generators. Because a limited number of organo-azo, $-\mathrm{N}-\mathrm{N}$-, compounds are marketed as free radical generators, many of the arguments and considerations detailed in this report for the compatibility of organic peroxides with polyethylene containers will also apply to free radical generating organo-azo compounds.

Independent of container type, compatibility with organic peroxide formulations will ultimately be judged on the success or failure of the plastic container to meet permeability, leakage, and strength criteria. Consequently, many of the points of discussion presented in sections 4.2, 4.4, 4.5 and 4.6 developed for high density polyethylene (HDPE) will also apply to the permeability, oxidative susceptibility, and stabilization of other polyethylenes used within self-supporting and composite containers. We believe therefore that solute/solvent permeation and embrittlement due to polymer oxidation will also need to be examined for other polyethylenes in the future since these materials are also used for peroxide packaging.

\subsection{COMMERCIAL ORGANIC PEROXIDES: FORMULATIONS AND PLASTICS PACKAGING}

We have surveyed the literature and have found that there are numerous domestic producers of organic peroxide compounds. From this list, we have been in contact with representatives from over six corporations, including all of the major producers. These 
include: Akzo Chemicals Inc.; Atochem North America, Inc., Organic Peroxides Div.; Catalyst Resources Inc.; and Witco Corp., U.S. Peroxygen Products. Though a single corporation may not market the entire range of some 175 commercially available organic peroxides, our research does reveal that within any one peroxide class, only a limited number of chemical compounds exist, many of which are common to multiple producers and suppliers.

We have also surveyed many of the major polyethylene drum and container manufacturers, representatives of the Plastic Drum Institute, a division of the Society of Plastics Industries, and with many of the major suppliers of the polyethylene resin. The purpose of these inquiries was to ascertain the methods and practices used to assess container - organic peroxide compatibility, container types, and methods of container fabrication and resins involved.

\subsubsection{Classification of Organic Peroxides Organic peroxides can be classified according to} chemical structure. In a general sense, there exist two principle groupings within this classification scheme: organo-hydroperoxides and organo-organo peroxides. Table 4.1 lists the various organic peroxide classes, characteristic chemical structure, and types of diluents within which peroxides from each class are dispersed or dissolved. Throughout this section, continual reference to peroxide class will be made with the hope of simplifying our discussions.

\subsubsection{Polyethylene Packaging of Organic Peroxides We have discussed organic peroxide} packaging considerations with producers of organic peroxides, manufacturers of plastic containers, and suppliers of the polymer resin. We have found that high $(\rho \geq 0.945)$, medium $(0.932 \leq \rho \leq 0.942)$, low, and linear low $(\rho \leq 0.932)$ density polyethylene as well as crosslinkable polyethylene (PE) resins are all used for the packaging of organic peroxides. Plastic containers without an exterior support, such as drums and jerricans, appear to be made primarily of high density polyethylene, HDPE, though thermally cross-linked polyethylene is also used. Composite containers that incorporate an exterior support structure with an inner bladder are almost exclusively constructed using low density polyethylene, LDPE, bladders.

Linear polyethylene resins are processed into containers using blow molding techniques whereas cross-linked PE containers are made using rotation molding of low molecular weight ethylene copolymer resin which is then chemically cross-linked using organic peroxides. Most container makers asserted that little difference in molding characteristics and final container performance properties exist between resins from different suppliers. However, little or no comment was made regarding the long term oxidative stability of the resin or container, with the exception of one container manufacturer. It was the expressed belief of this manufacturer that variations in resin antioxidant and stabilizer compounding which takes place during resin manufacture and/or container fabrication cause distinctions to arise in the long term peroxide-container compatibility of comparable resins from different suppliers. This conclusion is based on results from their own chemical and mechanical compatibility testing facility; a facility rather unique within the plastic container manufacturing community. 
Table 4.1

Classification of Organic Peroxides

Peroxide

Name

General Structure $^{(a)}$

Diluents $^{(\mathfrak{b})}$

Class

I hydroperoxides

$\mathrm{RO}-\mathrm{OH}$

water; water/tbutyl alcohol; water/t-a m y 1 alcohol

II dialkylperoxides

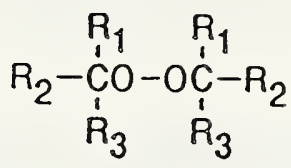

$\mathrm{CaCO}_{3} ;$ burgess clay; OMS; DOP; polypropylene powder; neat solid \& liquid

III

diacyl peroxides

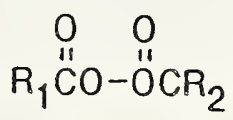

D C P ; T C P ; $\mathrm{DMP}+\mathrm{IBI}$; silicon oil; inorganic phosphates; water; wheat starch; neat solid

IV

peroxyesters

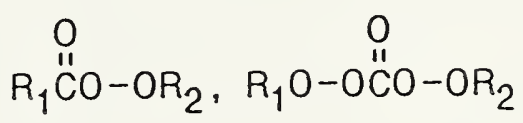

BBP; DBP; DOP; OMS; toluene; neat liquid

V peroxydicarbonates

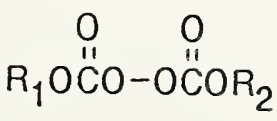

decane; OMS; trichloroethylene; toluene; neat liquid

VI ketone peroxides

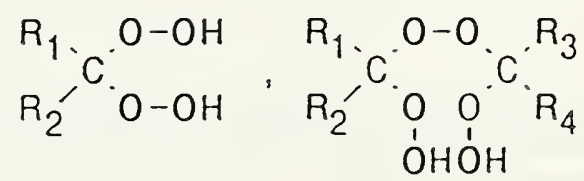

D M P ; e thy l acetate; TEP/DEG 
Table 4.1 (continued)

Classification of Organic Peroxides

$\begin{gathered}\text { Peroxide } \\ \text { Class }\end{gathered}$ Gameneral Structure

VII peroxyketals

$$
\begin{aligned}
& R_{1}=O-O R_{3} \\
& R_{2} O-O-O R_{4}
\end{aligned}
$$

BBP; Burgess clay; $\mathrm{CaCO}_{3} ; \quad \mathrm{DBP}$ $\mathrm{DOP}$; inert filler; OMS; neat liquid

VIII peroxyacids water; acid solutions

a) $\quad \mathrm{R}=$ alkyl, aryl; $\mathrm{R}_{1}=$ or $\neq \mathrm{R}_{2}=$ or $\neq \mathrm{R}_{i}$.

b) BBP- butylbenzyl phthalate; DBP- dibutyl phthalate; DCP- dicalcium phosphate; DEG- diethylene glycol; DMP- dimethyl phthalate; DOP- dioctyl phthalate; IBIisobutyl isobutyrate; OMS- odorless mineral spirits; TCP-tricresyl phosphate; TEP- triethyl phosphate. 


\subsubsection{Currently Implemented Compatibility Testing Methods From our inquiries, it is}

clear that the vast majority of organic peroxide producers do not conduct container compatibility testing. Virtually all, in fact, rely on the recommendations of the container manufacturer to insure 49 CFR Part 107, et al. compliance. Producers frequently indicated that, given no new peroxide formulations have been introduced for some time and that plastic container failure seems not to be a problem, peroxide compatibility testing is not conducted.

Discussions with numerous large and small plastic container manufacturers and the Plastic Drum Institute, a division of the SPI, indicate questions regarding compatibility of a new lading with polyethylene are most always directed to the resin manufacturer. Resin compatibility is decided depending on whether the lading compound is listed on a compatibility chart which is marketed with each resin. If the resin manufacturers have not themselves tested the lading in question, they will not make any recommendations. Inquiries directed to the polyethylene producers indicate that little new chemical compatibility testing is currently conducted and that often the compatibility charts are based on very old data. It is important to note that little if any exact organic peroxide - solvent pair chemical testing has ever been conducted by the resin producers.

When compatibility testing is conducted by a container manufacturer, we have found that nearly all companies conduct their tests according to 49 CFR Part 178 guidelines, and nothing more. Consequently, the long term chemical compatibility of a container with organic peroxides is not thoroughly examined as more fully discussed in section 4.7.2. This point becomes more important as container reuse practices become more prevalent. Discussions with the Plastic Drum Institute (PDI) indicates that the Institute does have a committee concerning itself with organic peroxides. Conversation with the Institute does indicate, however, that the PDI does not make testing recommendations for organic peroxide - container compatibility to the individual drum producers. One plastic container manufacturer was found, however, that does conduct a variety of chemical, mechanical, and permeation testing of their own to insure container compatibility. This though was the exception.

In summary, our surveys have indicated that little compatibility testing beyond 49 CFR Part 178 between an exact organic peroxide - diluent formulation with polyethylene has or is being conducted. This includes the producers of organic peroxides, the manufacturers of plastic containers, or the producers of the resins themselves. The chemical resistance against oxidation of a resin formulation is therefore not well known.

\subsection{PERMEATION THROUGH POLYETHYLENE}

4.2.1 Organic Peroxides The vast majority of the commercial organic peroxides are not expected to diffuse strongly or interact unadvantageously with high density polyethylene in their undisassociated state. There are, however, exceptions which may uniquely complicate the oxidative stability of polyethylene containers.

Table 4.2 lists examples from each peroxide class along with the respective calculated Permacor $\pi$-value [2], dissolution or dispersing solvent, self accelerating decomposition temperature, SADT [11], and activation, $\mathrm{E}_{\mathrm{a}}$, energy for dissociation. In compiling these data, attention was directed towards those commercially available compounds within each 
peroxide class showing the smallest calculated Permachor values. In other words, the purpose is to assess the potential for solvent unassisted permeation of organic peroxides through high density polyethylene. Because Salame's original table of $\pi$-values does not include groupings such as peroxy, hydroperoxy, carbonate, etc. [2], two ether linkages were taken to be equivalent to a peroxy linkage, an ether plus alcohol was equivalent to a hydroperoxide, and an ether plus an ester was equivalent to a peroxyester group, etc. for calculating $\pi$-values. Though such substitutions may introduce errors in calculated $\pi$-values, the exercise becomes nonetheless very useful.

Examination of Table 4.2 reveals a wide spread in minimum calculated $\pi$-values, ranging from 12.8 for di-t-butylperoxide to 36.8 for methylethylketone peroxide. Close to di-t-butylperoxide, a dialkylperoxide (Class II), is t-butylperoxy pivalate, 14.5, a peroxyester (Class IV). Listings in Table 4.2 showing a range in $\pi$-values are ones that both exclude and include the affects of a branched, tertiary carbon center. Both di-t-butylperoxide and tbutylperoxy pivalate have minimum $\pi$-values similar to that of methylethylketone, n-butyl acetate, and acetone; all strong polyethylene physical permeants [1].

Beyond the uncertainty regarding the true Permachor value for peroxy and other linkages, another highly important consideration is missing from the Salame's work [2] as it applies to organic peroxides. Namely, to what extent do single or multiple small chain branch sites, such as a tert-, iso-, or sec- carbon centers, increase the compound $\pi$-value and diminish its permeability? Examination of Salame's original data show only two polar branched compounds were tested versus the linear homolog; n-butyl, sec-butyl, tert-butyl alcohol and n-amyl, iso-amyl propionate. In the first case, observed permeation $\mathrm{P}$-factors were appreciably higher above $21^{\circ} \mathrm{C}$ than expected values based on calculated $\pi$-values. In the second compound, only estimates of P-factors are included.

The available permeation data suggest that materials with calculated $\pi$-values above 20 will not rapidly permeate through polyethylene. Therefore, hydroperoxides (Class I), ketone peroxides (Class VI), peroxyketals (Class VII), peroxyacids (Class VIII), and nearly all diacyl peroxides (Class III) and peroxycarbonates (Class V) are not predicted to be strong physical diffusants in they themselves. It is important to note that within Class II and IV, the cited compounds are not the only examples with low $\pi$-values. For example t-butyl cumylperoxide $(\pi=17.2)$, t-butylperoxy acetate $(\pi=15.4)$ and t-amylperoxy pivalate $(\pi=15.5)$ would likely show significant polyethylene permeability too. Consequently, the permeation of undisassociated organic peroxides through polyethylene is of highest concern for the simpler, lower molar mass members of both the dialkylperoxide and peroxyester classes.

Both di-t-butylperoxide and t-butylperoxy pivalate are in the form of liquids, the later using odorless mineral spirits (OMS) as solvent. The potentially low $\pi$-values of OMS (non singular value and always compositional dependent) means that both peroxide and solvent may act as physical diffusants. Consequently, especially in the case of di-t-butylperoxide and the lower peroxyester family members, an extremely high probability exists that both solvent and peroxide will permeate throughout the polyethylene container and bleed to the container exterior. Such a situation will create further container compatibility complications due to possible photolytic decomposition of peroxides which accumulate on the container exterior. This condition may also create a detonation hazard. 
Table 4.2

Permachor ( $\pi$ ) Values and Thermal Stability Data for Lowest Peroxide Family Members

\begin{tabular}{|c|c|c|c|c|}
\hline Class & Compound & Solvent ${ }^{(\mathbf{a})}$ & $\begin{array}{c}\text { Value }^{\text {(b) }} \\
\text { Valc }\end{array}$ & $\begin{array}{l}\mathrm{SADT},{ }^{\circ} \mathrm{C} \\
\text { (c) }[11]\end{array}$ \\
\hline
\end{tabular}

I<smiles>CC(C)(C)OO</smiles>

t-butyl hydroperoxide

II<smiles>CC(C)(C)OC(C)(C)C</smiles>

di-t-butylperoxide

III<smiles>O=C(Oc1ccccc1)c1ccccc1</smiles>

silicone oil, TCP, water; neat solid

dibenzoyl peroxide

IV

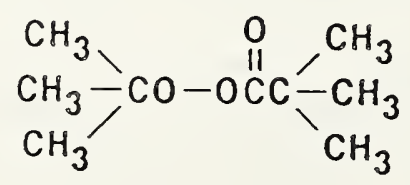

t-butyl peroxypivalate

$\begin{array}{cc}20.4 & 80^{\circ} \\ \text { to } & 88^{\circ} \\ 22.4 & \end{array}$

$98 \%$ pure

12.8

$80^{\circ}$

151

to

130.5

16.8

$19.0 . \quad \geq 54^{\circ}$

113.4
OMS

14.5

to

18.5
105.8

117.6 
Table 4.2 (continued)

Permachor $(\pi)$ Values and Thermal Stability Data for Lowest Peroxide Family Members

Class

Compound

Solvent ${ }^{(a)}$

Value $^{\pi-}$

SADT, ${ }^{\circ} \mathrm{C}$

(c)[11] $\mathrm{kJ} / \mathrm{mol}$

V

$$
\begin{gathered}
\stackrel{O}{\mathrm{C}_{3} \mathrm{H}_{7} \mathrm{OCO}-\mathrm{OCOO}_{3} \mathrm{H}_{7}} \\
\text { di-n-propyl } \\
\text { peroxydicarbonate }
\end{gathered}
$$

decane,

19.0

$-1^{\circ}$

$-121$

trichloro-

ethylene

VI

$$
\mathrm{CH}_{2} \mathrm{H}_{5}, \mathrm{O}, \mathrm{O}-\mathrm{OH}
$$

OMS
36.8
to

$38.8^{(e)}$

methylethylketone

peroxide $^{(\oplus)}$

VII

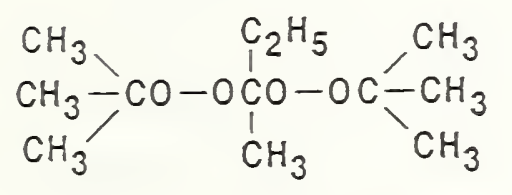

DOP

21.6

to

27.6

2,2-bis-t-butylperoxy butane

VIII<smiles>C[14C](=O)OO</smiles>

water \& acetic

28.1

acid

peroxyacetic acid

(a) DMP- dimethylphthalate; DOP- dioctylphthalate; OMS- odorless mineral spirits; TCPtricresylphosphate.

(b) Reference 2.

(c) Self-Accelerating Decomposition Temperature: The lowest ambient oven temperature at which a peroxygen composition in its largest commercial package will undergo selfaccelerating decomposition is established.

(d) Mixture of monomer, dimer, trimer, etc.

(c) Assumes monomeric structure. 
4.2.2 Dispersants and Solvents As seen in Table 4.1, organic peroxides are marketed in both solid and liquid physical forms. Though frequently compounded with diluents and binders, pure or "neat" organic peroxides are also commercially available. Reviewing the various classes of organic peroxides listed which are compounded with liquid diluents, Table 4.1 also demonstrates the wide variety of organic chemicals used for either dissolving or dispersing the parent peroxide compound. We believe this creates two very important concerns.

Firstly, examination of the solvents used for packaging organic peroxides from the viewpoint of polyethylene permeability reveals that many of the compounds used are known physical diffusants, causing in many instances swelling and mass uptake. Table 4.3 lists the calculated Permachor $\pi$-values for many of the solvents and liquid dispersants listed in Table 4.1. Since Salame [2] does not include the phosphate linkage, Si-Si and Si-O bonds, and water, $\pi$-values for solvents which contain these groups can not be calculated. Also, because odorless mineral spirits is a mixture of low molar mass hydrocarbons it too has not been included. As is seen, many solvents have calculated $\pi$-values below 20; the point below which diffusion and loss of liquid becomes an important concern with HDPE.

It is important to acknowledge that in Salame's [2] original work, certain types of compounds gave either erroneously high or low experimental permeation P-factors relative to the expected values based on the calculated $\pi$-value. Such deviations become most apparent at higher temperatures. Of the solvents listed in Table 4.3, BBP, DMP, DOP, IBI, and trichloroethylene were not examined by Salame. Acetic acid, t-amyl alcohol, DBP, decane, ethyl acetate, and toluene gave good agreement up to $74^{\circ} \mathrm{C}$. t-Butyl alcohol and diethylene glycol, on the other hand, both showed markably greater experimental P-factors than were calculated. Both are polar compounds capable of hydrogen bonding; a point which Salame believes is important. In addition to t-butyl alcohol, sec-butyl alcohol also showed much . larger $\mathrm{P}$-factors at $54^{\circ} \mathrm{C}$ and $74^{\circ} \mathrm{C}$. Therefore, highly polar compounds frequently give larger permeation factors than expected.

Secondly, it is important to differentiate the two possible physical forms of the peroxide compound itself, ie. is the material molecularly dissolved in the compounding solvent or is it finely dispersed as a solid within a liquid medium. In the former case, the possibility of the peroxide diffusing into the polyethylene container in conjunction with the dissolving solvent enhances the likelihood of chemical action by the peroxide or its dissociated free radicals on the polyethylene. In contrast, peroxide attack of polyethylene in the latter case is diminished because of limited molecular polymer-peroxide contact. Of course, if dissociated free radicals arising from thermally or catalytically activated peroxide decomposition are soluble in the dispersing solvent, a situation analogous to the first scenario is likely. 
Table 4.3

Calculated Permachor $\pi$-Values for Select Solvents Used for the Marketing of Commercial Organic Peroxides

\begin{tabular}{|c|c|c|}
\hline Solvent ${ }^{(a)}$ & $\begin{array}{c}\text { Applicable Peroxide } \\
\text { Classes }\end{array}$ & $\begin{array}{c}\text { Permachor }(\pi)- \\
\text { Values }\end{array}$ \\
\hline acetic acid & VIII & 15.5 \\
\hline t-amyl alcohol & I & 21.0 \\
\hline $\mathrm{BBP}$ & IV, VII & 20.9 \\
\hline t-butyl alcohol & I & 20.0 \\
\hline DBP & IV, VII & 20.9 \\
\hline DMP & III, VII & 13.6 \\
\hline DOP & II, IV, VII & 27.6 \\
\hline decane & V & 10.0 \\
\hline diethylene glycol & VI & 34.4 \\
\hline ethyl acetate & VI & 12.0 \\
\hline IBI & III & 11.1 \\
\hline toluene & IV, $\mathrm{V}$ & 6.4 \\
\hline trichloroethylene & V & 5.4 \\
\hline OMS & II, III, IV, V, VII & - \\
\hline silicone oil & III & - \\
\hline
\end{tabular}


Table 4.3 (continued)

Calculated Permachor $\pi$-Values for Select Solvents Used for the Marketing of Commercial Organic Peroxides

Solvent ${ }^{(a)}$

Applicable Peroxide

Classes

Permachor $(\pi)$ -

Values

$\begin{array}{cc}\text { TCP } & \text { III } \\ \text { TEP } & \text { VI } \\ \text { water } & \text { I, III, VIII }\end{array}$

(a) BBP- butylbenzyl phthalate; DBP- dibutyl phthalate; DMPdimethyl phthalate; DOP- dioctyl phthalate; IBI- isobutyl isobutyrate; OMS- odorless mineral spirits; TCP- tricresyl phosphate; TEP- triethyl phosphate. 
In comparing identical peroxide compounds originating from different sources, it was discovered that the same diluent is not always used for dispersing or dissolving the parent compound. In fact, many times an individual firm will market multiple forms of the same peroxide, varying the peroxide concentration and/or nature of diluent. Such large variations in diluent type and concentration within the various peroxide classes heighten our concern that peroxide permeability and reactivity in combination with diluent composition may prove to be the governing parameter in describing the compatibility of these and similarly related reactive compounds with container grade polyethylene.

\subsection{PEROXIDE CHEMISTRY AND DECOMPOSITION PATHWAYS}

\subsubsection{Compound Stability Most all organic peroxides are photo- and thermally sensitive} because of the weak oxygen-oxygen bond. The thermal decomposition kinetics are controlled by the $\mathrm{R}$ groups which make up the molecule. The peroxide class and its decomposition pathway define the type of organo free radical that is produced. The impact of chemical structure on the stability of the nascent organic peroxide compound can be seen by inspecting the range of ten-hour half-life temperature $\left(\mathrm{t}_{1 / 2}^{1 \text { ohrs. }},{ }^{\circ} \mathrm{C}\right)[12]$ values for commercial compounds from the various organic peroxide classes as shown in Table 4.4. From this survey, the thermal stability of organic peroxides by class, excluding ketone peroxides and peroxyacids, against decomposition and free radical formation may be viewed to decrease in the following order.

$$
\mathrm{I}>\mathrm{II} \approx \mathrm{VII}>\mathrm{IV}>\mathrm{III} \approx \mathrm{V}
$$

Individual peroxide compounds may not, however, follow this ranking order. From a viewpoint of free radical induced failure of polyethylene packaging, this ranking does alert us to the possibility that free radical concentration and consequently polyethylene degradation kinetics at any given temperature may follow the reverse order, making diacylperoxides, peroxydicarbonates and peroxyesters most unstable. This argument takes into account radical concentration and does not reflect differences in radical reactivity. It also does not consider ketone peroxides and peroxyacids since decomposition data could not be obtained.

\subsubsection{Homolytic and Catalytic Decomposition and Radical Reactivity Depending on the} class of peroxide in question, a multitude of radical and non-radical generating decomposition pathways exist. Homolytic decomposition refers to the thermal or ultra-violet initiated dissociation of the parent compound which nearly always gives rise to free radical formation. Catalytic decomposition, on the other hand, depends on the presence of secondary agents, generally mineral acids or bases, multivalent metals, or other free radicals, and often times gives a mixture of free radical, ionic, and/or oxidized and reduced products. Consequently, both homolytic and catalytic pathway mechanisms are of concern for the survivability of polyethylene containers.

Peroxides show a wide variation in thermal sensitivity depending on the structure of the $\mathrm{R}$ groups. The relative reactivity of radicals can be correlated with the hydrogen bond dissociation energies of the parent compound. The higher the bond dissociation energy, the 
less stable and more reactive is the corresponding radical that is formed by removing the hydrogen atom. Table 4.5 lists the hydrogen bond dissociation energies for many of the types of radicals formed from the decomposition of organic peroxides. Thus tertiary alkyl radicals $\left(\{\mathrm{R}\}_{3} \mathrm{C} \bullet\right)$ are less reactive (more stable) than secondary alkyl radicals $\left(\left\{\mathrm{R}_{2}\right\} \mathrm{CH} \bullet\right)$ which are less reactive (more stable) than primary alkyl radicals $\left(\mathrm{RCH}_{2}{ }^{\bullet}\right)$. Table 4.5 shows that the methyl radical $\left(\mathrm{CH}_{3} \bullet\right)$ is more reactive than other primary alkyl radicals and is about as reactive as alkoxy $(\mathrm{RO} \bullet$ ) radicals. Consequently, only organic peroxides which decompose to form free radicals which are more reactive than secondary alkyl radicals (398 $\mathrm{kJ} / \mathrm{mol}$ ) are expected to directly attack polyethylene and result in molecular degradation. In other words, many of the commercial organic peroxides give rise to radical species on dissociation that are of sufficient reactivity to chemically modify polyethylene. This argument does not take into account complication which will arise in the presence of molecular oxygen.

Table 4.4

Ten-Hour Half-life Temperatures ${ }^{(a)}$ and Radical Type Formed for the Thermal Decomposition of Organic Peroxides according to Peroxide Class

Class - Name $\mathrm{t}_{1 / 2}^{1 \text { ohrs. }},{ }^{\circ} \mathrm{C}$

$122-172$

$90-130$

$61-73$

$35-115$

$40-75$

NA
$93-115$

NA
Radical Formed
VI - Ketone Peroxides

VII - Peroxyketals

VIII - Peroxyacids

V - Peroxydicarbonates

(a) Ref. 12 
Table 4.5

Relative Reactivity of Radicals

Species

Bond

Dissociation

Energy, $\mathrm{kJ} / \mathrm{mol}$
Radical

Reactivity

(increasing order)

$\begin{array}{ccc}\{\mathrm{R}\}_{3} \mathrm{C} \sim \mathrm{H} & 381 & \text { lowest } \\ \{\mathrm{R}\}_{2} \mathrm{CH} \sim \mathrm{H} & 398 & \downarrow \\ \mathrm{RCH}_{2} \sim \mathrm{H} & 410 & \downarrow \\ \mathrm{CH}_{3} \sim \mathrm{H} & 435 & \downarrow \\ \mathrm{RO} \sim \mathrm{H} & 435 & \downarrow \\ \mathrm{C}_{2} \mathrm{H}_{5} \mathrm{OO} \sim \mathrm{H} & 460 & \downarrow \\ \mathrm{CH}_{3} \mathrm{OO} \sim \mathrm{H} & 469 & \downarrow \\ \mathrm{HO} \sim \mathrm{H} & 498 & \text { highest }\end{array}$


In the following section, a review of peroxide decomposition pathways according to peroxide class and primary radical species formed is presented [9].

Class I - Hydroperoxides: Thermal or UV induced unimolecular homolysis yields alkoxy $(\mathrm{RO} \bullet)$ and hydroxy $(\bullet \mathrm{OH})$ free radicals in a straightforward manner. Alkoxy beta-scission can lead to ketone formation and creation of alkyl $(\mathbb{R} \bullet)$ radicals. The propensity for this to occur depends strongly on the nature of the alkyl (R) group. Consequently, t-amyloxy radical beta-scission giving ethyl radicals will proceed more rapidly than the corresponding reaction involving the t-butoxy radical.

Catalytic decomposition giving radical products is induced by pre-existing free radicals and multivalent metals such as iron, copper, cobalt, and manganese. Transition metal complexes will undergo an one-electron oxidation in the presence of organic hydroperoxides. Products from these pathways include alkyl peroxy (ROO•), alkoxy, and hydroxy radicals in addition to hydrocarbon, ether, alcohol, hydroxy anion, and hydrogen cation by-products.

Class II - Dialkyl Peroxides: Homolytic cleavage produces alkoxy (RO•) radicals which can undergo a secondary, rather slow, beta-scission reaction. Primary $\left(\mathrm{CH}_{3}{ }^{\bullet}\right)$ and secondary $\left(\mathrm{RCH}_{2} \bullet\right)$ alkyl radicals ensuc. Consequently, both alkoxy and alkyl radicals are available for polyethylene altack. Di-t-butyl alkyl peroxides are unaffected by strong bases. Strong oxidizing and reducing agents can decompose ionically these materials forming non-radical by-products.

Class III - Diacyl Peroxides: Thermal homolysis initially yields acyloxy $\left(\mathrm{R}\left\{\mathrm{CO}_{2}\right\} \bullet\right)$ radicals which rapidly undergo decarboxylation to give the corresponding alkyl $(R \bullet)$ radical. Given the scope of commercial organic diacyl peroxide examples, primary, secondary, tertiary alkyl and aryl radicals can result. Free radical induced decomposition of diacyl peroxides produces an ester and another acyloxy radical, with no net change in radical concentration. Many diacyl peroxides undergo an intramolecular carboxyl inversion in the presence of strong acids and polar solvents followed by dehydration to produce non-radical products. Inorganic base hydrolysis forms acid and peroxyacid salts. Diacyl peroxide decomposition is also catalyzed by transition metal ions, $\mathrm{eg}, \mathrm{Cu}^{+}, \mathrm{Fe}^{2+}, \mathrm{Co}^{2+}$, and $\mathrm{Mn}^{2+}$ to give an acyloxy radical and carboxylate anions.

Class IV - Peroxyesters: Homolytic cleavage initially forms alkoxy (RO•) and acyloxy $\left(\mathrm{R}\{\mathrm{CO}\}_{2}\right)^{\prime}$ radicals which then undergo secondary reactions as outlined for both dialkyl and diacyl peroxides. Primary, secondary, or tertiary alkyl radicals are the resulting products. Pre-existing alkyl radicals can altack the -O-O-bond giving an ester and a single alkoxy radical. Mineral base hydrolysis of peroxyesters form the alkali metal salt of the acid and hydroperoxide which can decompose as described above. Electron-transfer decomposition involving transition metals give non-radical by-products and alkoxy radicals.

Class V - Peroxydicarbonates: Thermal homolysis proceeds similarly to that for diacyl peroxides, first forming $\left.\mathrm{RO}_{2} \mathrm{CO}_{2}\right\}$ intermediates which quickly decarboxylate to lorm the 
corresponding alkoxy (RO•) radical. Decomposition is accelerated by certain metals, concentrated sulfuric acid, and amines. Like diacyl peroxides, peroxydicarbonates are very susceptible to radical-induced decomposition giving non-radical and alkoxy radical byproducts. No net increase in radical concentration occurs. Similar transition metal catalyzed decomposition occurs in peroxydicarbonates as with diacyl peroxides.

Class VI - Peroxyketones \& VII - Peroxyketals: Both peroxide classes undergo complex decomposition pathways giving a mixture of products, eg, ketones, esters, carboxylic acids, hydrocarbons, and hydrogen peroxides. The later generates free radicals in accordance with Class I compounds. In addition, peroxyketals may thermally dissociate to both alkoxy and alkyperoxy (ROO•) radicals. Both compound classes undergo transition metal catalyzed decomposition giving both non-radical and radical species.

Class VIII - Peroxyacids: Organic peroxyacids are the most powerful oxidizing agent of all organic peroxides and are not noted for their stability and many lose active oxygen on standing. Hydrolysis leads to the parent acid and hydrogen peroxide. The later decomposes to hydroxy $(\bullet \mathrm{OH})$ radicals. Hydrolysis is accelerated by the presence of strong acids or bases. Thermal decomposition of peroxycarboxylic acids can proceed forming free-radical $(\bullet \mathrm{OH})$ and non-radical products. Catalytic decomposition occurs via pre-existing radicals, metals, metal ions, metal complexes. One-electron transfers occur with transition metals in the same manner as with hydroperoxides.

\subsubsection{Polyethylene Cross-linking using Organic Peroxides Organic peroxides are} commonly used to affect the controlled modification of physical properties of polyolefins, including polyethylene. Controlled crosslinking can improve rigidity, creep resistance, environmental stress-cracking resistance, and reduce gaseous permeability. Whereas polyethylene will undergo oxidative degradation via the transformation of alkyl radicals into oxygenated species, cross-linking reactions take place in an essentially limited oxygen environment. Some organic peroxide plastic containers are constructed of crosslinked polyethylene.

Although a wide variety of peroxy-compounds is known, only those that can abstract hydrogen atoms from $\mathrm{C}-\mathrm{H}$ groups are effective cross-linking agents. Peroxide classes commercially employed include: hydroperoxides (I), dialkyl peroxides (II), diacyl peroxides (III), peroxyesters (IV), and peroxyketals (VII).

\subsection{FREE RADICAL OXIDATION OF POLYETHYLENE}

Commercial polyolefins, including high density polyethylene (HDPE), form an import class of thermoplastic structural materials. The usefulness of polyolefins is severely limited by degradation reactions which normally occur on exposure of the polymer to oxygen. This is markedly accelerated by both heat and ultra-violet exposure, and will lead to embrittlement of the polymer. A striking feature of polyolefin oxidation is that relatively little chemical change is needed to effect major changes in its physical properties. For example, the absorption of less than one oxygen molecule for every hundred repeat units will give rise to a 
two to three fold reduction in molecular weight and will result in total embrittlement of unstabilized polymer [19]. Such an effect has its origins in the semicrystalline nature of most all polyolefins and is the result of selective oxidation of the interlamellar amorphous phase.

In this section, we will examine many of the important aspects of free radical based oxidation of polyethylene. Because of the prominent role oxygen plays in affecting the mechanistic pathways of free radical based degradation of polyethylene, it becomes important to examine what secondary factors will influence the concentration of oxygen in polyethylene containers (section 4.5).

\subsubsection{Radical Attack on Unstabilized Polyethylene The oxidation of saturated polyolefins} involving molecular oxygen is autocatalytic and proceeds via a free radical process. Under normal conditions, the initial product is a hydroperoxide $(\mathrm{ROOH})$ moiety which later decompose to free radicals that initiate the chain reactions. These hydroperoxides are generated as a result of molecular oxygen adsorption into the polymer followed by single oxygen attack and represent the initiation process for polymer degradation. If free radicals of sufficient energy are already present, as would occur from the thermal dissociation of an organic peroxide, then propagation and termination pathways leading to chemical degradation may commence even in the absence of oxygen.

Initiation: Methyl $\left(\mathrm{CH}_{3} \bullet\right)$, alkoxy $(\mathrm{RO} \bullet)$, alkylperoxy $(\mathrm{ROO} \bullet)$, hydroxy $(\mathrm{HO} \bullet)$, and to lesser extent, n-alkyl radicals, e.g. $\left(\mathrm{C}_{2} \mathrm{H}_{5} \bullet\right)$, are all energetic enough to initiate proton abstraction from polyethylene (Reaction 1), thereby producing a macro-alkyl radical (I). In the presence of oxygen - with pressures exceeding ca. $100 \mathrm{~mm} \mathrm{Hg}$ - radical propagation and conversion to the corresponding macro-peroxy radical (II) is generally very rapid with an activation energy of about zero [13]. In the absence of diffusion limitations, this reaction is first order with respect to oxygen.

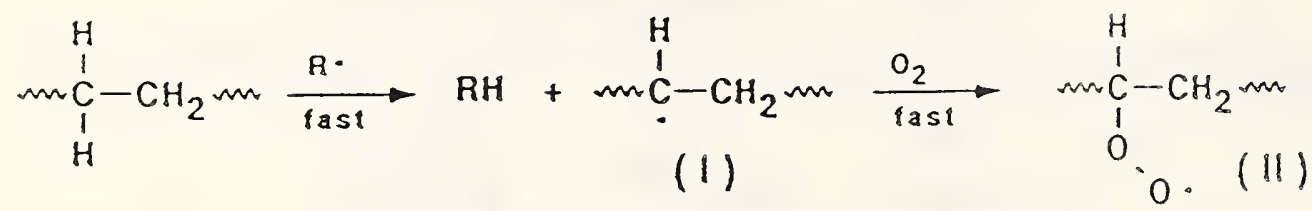

Propagation: After formation of macro-peroxy radicals (II), propagation by neighboring proton abstraction is likely (Reaction 2), via a six-membered ring transition state. This gives rise to further peroxygenated polymer. This propagation step is independent of oxygen concentration and creates a new macro-hydroperoxide (III) moiety and an additional macroalkyl (I) radical. The rate of reaction 2 is dependent on the reactivity of the $\mathrm{C}-\mathrm{H}$ site undergoing abstraction. In the liquid phase, the relative reactivities of tertiary and secondary $\mathrm{C}-\mathrm{H}$ bonds to t-butylperoxy radical attack are $18: 1$ at $30^{\circ} \mathrm{C}$, with primary $\mathrm{C}-\mathrm{H}$ groups being even less reactive than secondaries [14]. In the case of straight chain olefins, proton abstraction thereby generating (III) has an energy of activation of $\approx 29 \mathrm{~kJ} / \mathrm{mol}$ [13]. Thus, after initiation of a single macro-alkyl radical, propagation under normal thermal conditions 
and in the presence of oxygen will result in the production of many macro-hydroperoxide species before radical termination can occur.<smiles>CCC(C)CCC(C)OO</smiles>

Depending on the temperature and the availability of molecular oxygen throughout the material, chemical modification (cross-linking) and/or degradation (scission) of the polyolefin will proceed involving either macro-alkyl (I), macro-peroxy (II), or macro-alkoxy (IV) radicals as the dominate propagating species. It is the propagation and termination reactions of these radicals that result in a reduction in molecular weight, chemical cross-linking, formation of oxygenated macro-products, and an overall deterioration of material mechanical properties.

At low local concentrations of (III), thermally activated unimolecular decomposition with the formation of macro-alkoxy (IV) and hydroxy radicals occurs (Reaction 4.3). Chien has studied the thermal decomposition of stable polyethylene hydroperoxide and found that within the temperature range of $100^{\circ}$ to $135^{\circ} \mathrm{C}$, dissociation of (II) to (IV) obeys first order kinetics with more than $85 \%$ peroxide decomposition proceeding very rapidly with an $\mathrm{E}_{\mathrm{a}}=$ $104.6 \mathrm{~kJ} / \mathrm{mol}[15]$. Thermal history will therefore play a very important role in determining the extent to which oxidative propagation reactions within a polyethylene container proceed after container contact with initiating radical sources.

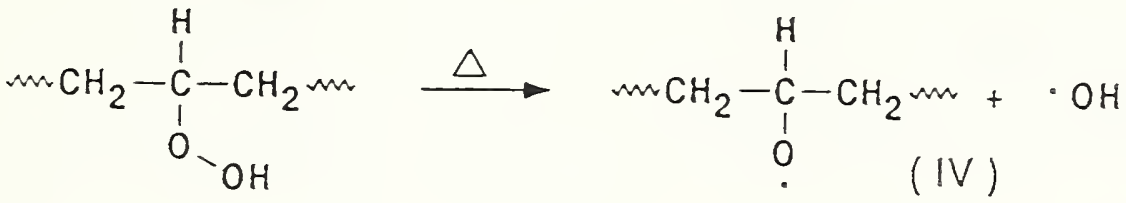

(Rx. 4.3)

Further propagation reactions following initiation may or may not result in chain scission or cross-linking. All of these reactions are responsible for the auto-catalytic behavior of polyolefin oxidation. For example, at high local hydroperoxide levels, as would be expected under high oxygen concentrations, a bimolecular decomposition to macro-alkoxy and macro-peroxy radicals can result (Reaction 4.4). This propagation reaction may or may not involve chemical neighbors and has the effect of generating additional radical species without a change in molecular weight. Macro-alkoxy radical proton abstraction can also occur producing stable oxygenated chromophores with commensurate radical regeneration (Reaction 4.5). In addition, these same species, (IV), can undergo beta-scission to produce additional oxygenated chromophores, a reduction in molecular weight, and regeneration of radicals (Reaction 4.6). 


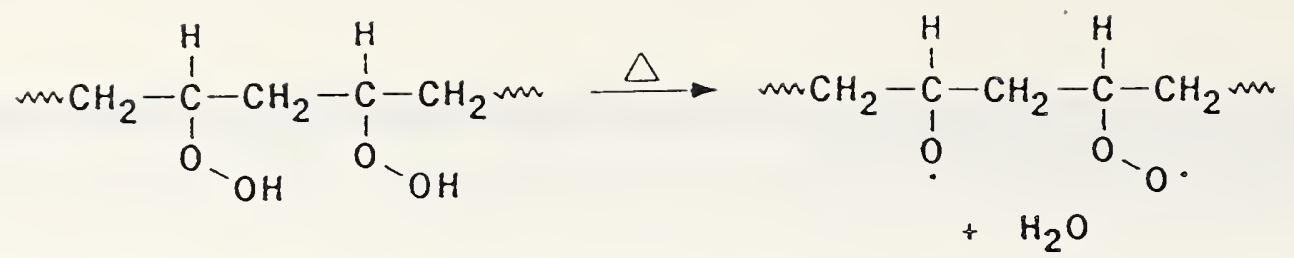

Termination: Termination reactions involve all three radical types (I, II, and IV) and proceed very rapidly for primary and secondary species with an $E_{2} \approx 12.6 \mathrm{~kJ} / \mathrm{mol}[13]$. Though in all cases termination reactions lead to stable products, these same reactions may also give rise to additional radicals. Chemical cross-linking and chain scission are the predominate results that are responsible for polymer embrittlement and mechanical failure. Concurrent formation of oxygenated and unsaturated chromophores can lead to enhanced photolytic instability and further accelerate degradation reactions.

In the absence of oxygen, bimolecular termination of macro-alkyl radicals predominates (Reaction 4.7). Under conditions of varying oxygen levels, for example when pressures exceeding ca. $100 \mathrm{~mm} \mathrm{Hg}$ are realized, reactions 4.8,4.9, and 4.11 will occur.
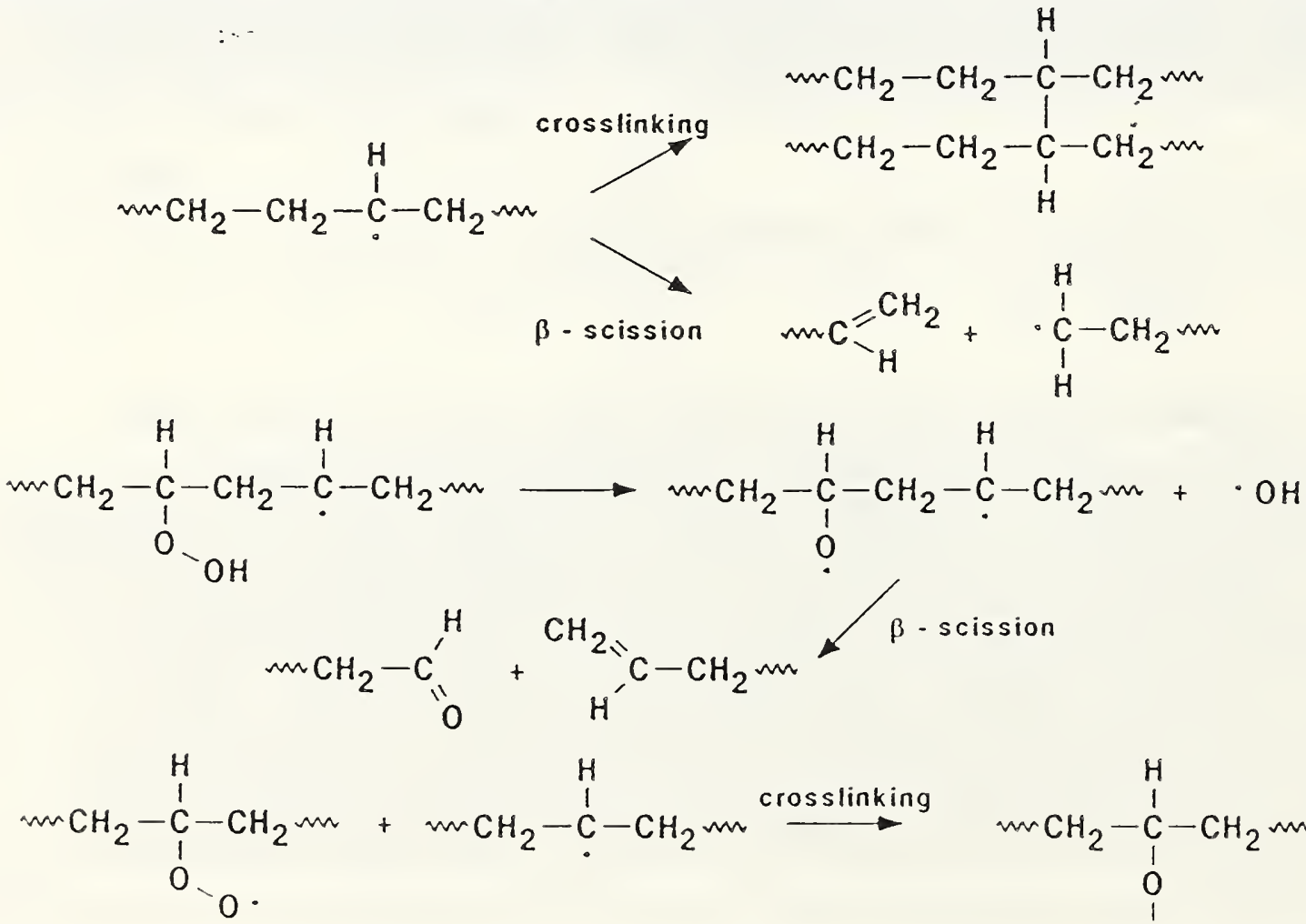<smiles>CCC(CC)OOC(CC)CC</smiles>

$(\mathrm{Rx}$.4.9) 


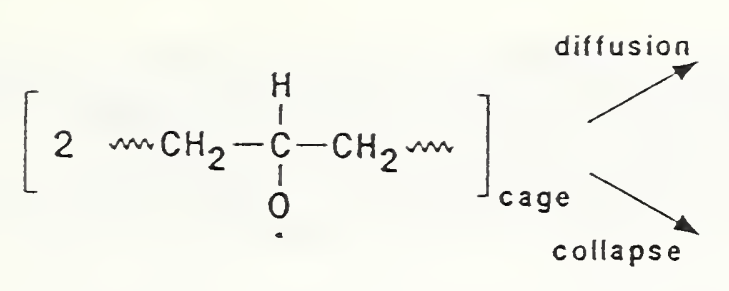

$2 \mathrm{maH}_{2}-\stackrel{\stackrel{\mathrm{H}}{\mathrm{C}}}{\mathrm{C}}-\mathrm{CH}_{2} \mathrm{~m}$<smiles>CCC(CC)OOC(CC)CC</smiles>

2

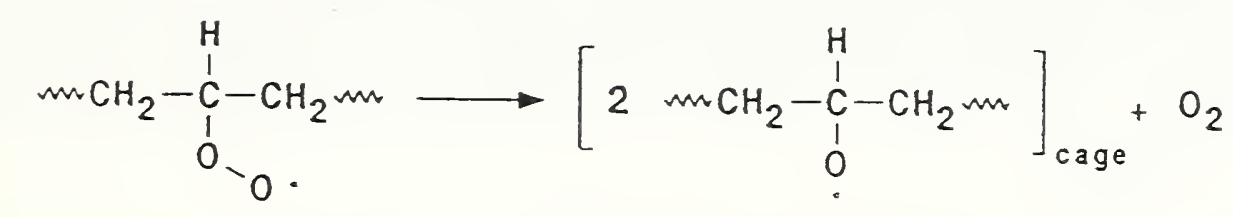

(Rx. 4.10)

It is important to note that although reactions 4.9 and 4.10 may form cross-linked polymer, a new macro-organic peroxide has been formed, whose energy of dissociation will vary with local structure. Thermal dissociation can occur leading to further polymer degradation (Reaction 4.11).<smiles>CCC(O)CCC1CC1</smiles>

In discussing the above reactions, it is important to note that other propagation and termination pathways are likely. Indeed, numerous studies have examined the formation of volatile, low molar mass products as a means of studying polyolefin degradation [20]. These include aldehydes, esters, water, carbon dioxide, and the like. However, as reported by Baum, chemical cross-linking and chain scission of polyethylene occur simultaneously even at very low levels of oxidation [16].

Under normal conditions of polymer oxidation, ie. in the absence of radical sources, an induction period corresponding to the initial formation of polymer hydroperoxide radicals takes place. Kinetic studies have shown that subsequent decomposition of hydroperoxide species representing propagation and termination pathways become autocatalytic [17]. It is important to note that activation energies reported for polyethylene oxidation are generally derived from analysis of the temperature dependence of this induction period. Hawkins et al. report that for temperatures ranging from $60^{\circ}$ to $140^{\circ} \mathrm{C}$, a linear relationship for both high density and low density polyethylene is observed, with $\mathrm{E}_{\mathrm{a}}$ values of 108.8 and $90.4 \mathrm{~kJ} / \mathrm{mol}$ respectively [18]. Similarly, Grieveson and coworkers using a medium density Zeigler-Natta polymerized polyethylene observe between $80^{\circ}$ and $125^{\circ} \mathrm{C}$ an activation energy of $87.9 \mathrm{~kJ} / \mathrm{mol}$ via oxygen absorption methods [19]. However, if an abundance of organic radicals are 
present due to thermal decomposition of organic peroxides, induction periods as discussed thus far would not be observed. Thus, after oxidation initiation by disassociated organic peroxides, the rate controlling process will be the thermal dissociation of macrohydroperoxide groups, analogous to the study of Chien $[15]\left(E_{2} \approx 105 \mathrm{~kJ} / \mathrm{mol}\right)$, leading to autocatalytic degradation.

\subsection{PHYSICAL FACTORS AFFECTING POLYETHYLENE OXIDATIVE STABILITY}

Beyond the energy and mechanistic considerations discussed in section 4.4, numerous physical factors impact the sensitivity of polyolefins to thermal oxidation. Many of these factors relate back to chemical and/or structural parameters while others may be due to nonstructural parameters. This section will discuss those factors applicable to the discussion of container grade polyethylene.

4.5.1 Morphology, Oxygen Absorption and Permeability In the absence of radical species, polyethylene samples when placed in an oxygen atmosphere will initially absorb oxygen at a relatively rapid rate, followed by a slower, steady rate. For thin films, the oxygen absorption rate is found to be related to the structure of the polyethylene and is proportional to the sample mass rather than the surface area [19], and decreases with increasing thickness [21]. For films thicker than $0.5 \mathrm{~mm}$, the oxidation rate is found to be proportional to sample surface area [19]. The permeability (P) of a gas is the product of the diffusion (D) and solubility (S) coefficients is a measure of the amount of gas that will flow through a film of the material, and has an energy of activation $\left(\mathrm{E}_{\mathrm{p}}\right)$ that is related to the energy of activation for diffusion $\left(\mathrm{E}_{\mathrm{d}}\right)$ and heat of solution $\left(\Delta \mathrm{H}_{\mathrm{s}}\right)[21]$.

$$
\begin{gathered}
P=D \times S \\
E_{p}=E_{d}+\Delta H_{s}
\end{gathered}
$$

For polyethylene, it is well established that low molar mass molecular diffusion occurs preferentially in the amorphous regions of the polymer because of the impermeability of the crystalline domains, even to oxygen. Hawkins et al. [18] reported that the rate of oxygen uptake in solid polyethylene during oxidation is inversely proportional to the percent crystallinity, indicating that only the amorphous regions in the semicrystalline polymer were susceptible to oxygen attack. For the same degree of oxidation in both types of polyethylene, on average there will be greater levels of oxidation in the amorphous regions of HDPE than in LDPE because of greater degrees of crystallinity commonly seen in HDPE. This explains the enhanced deterioration of mechanical properties of HDPE over LDPE at comparable levels of overall oxidation. Consequently, there is an inverse relationship between polymer density and oxygen diffusion coefficient [22]. Table 4.6 lists the solubility, diffusion coefficient, activation energy of diffusion, and heat of solution of oxygen in polyethylene [18]. It is interesting to note that $E_{d}$ is markedly smaller than the energy of activation for the initiation or propagation steps of oxidation. On the other hand, low oxygen 
solubility and diffusion coefficients offset this affect. Importantly, control of oxygen diffusion is facilitated at higher temperatures by the decrease of oxygen solubility.

An obvious effect of this condition is the nonuniform concentration of oxygen in polyethylene films, and consequently, a dependence of oxidation mechanism on film thickness. It has been shown that for very thin films, the oxidation rate appears to be independent of thickness, as measured by the variation of induction period, and that the limiting thickness decreases with increasing temperature of oxidation. At $125^{\circ} \mathrm{C}$, Grieveson et al. [19] reports a limiting thickness for uniform oxidation of unstabilized polyethylene of ca. $200 \mu \mathrm{m}$ whereas Billingham and coworkers [24] report at $90^{\circ} \mathrm{C}$ homogeneous carbonyl depth concentrations to ca. $250 \mu \mathrm{m}$. Under ambient conditions, Billingham [23] reports homogeneous aerobic oxidation for samples up to $1 \mathrm{~mm}$ in thickness.

Table 4.6

Solubility and Diffusion of Oxygen in Polyethylene at $25^{\circ} \mathrm{C}$ [22]
Polymer
Solubility
(ppm)
$\mathrm{D}$
$\left(10^{-7} \mathrm{~cm}^{2} \mathrm{~s}^{-1}\right)$
$\underset{\left(\mathrm{kJ} \mathrm{mol}{ }^{-1}\right)}{\mathrm{E}_{\mathrm{D}}}$
$\Delta \mathrm{H}_{\mathrm{s}}$
$\left(\mathrm{g} / \mathrm{cm}^{3}\right)$

(p)

.

\section{Amorphous $\quad 110$}

Semicrystalline

$\begin{array}{lllll}\rho=0.967 & - & 1.6 & - & - \\ \rho=0.964 & - & 1.70 & 36.8 & -1.7 \\ \rho=0.931 & - & 2.5 & - & - \\ \rho=0.915 & - & 5.4 & - & - \\ \rho=0.914 & - & 4.6 & 40.1 & 2.5\end{array}$


These considerations bring into focus two very important concerns. According to 49 CFR Parts 173.28 and 173.225 for reusable organic peroxide plastic containers, minimum wall thicknesses need to range from 1.2 to $2.2 \mathrm{~mm}$. Many organic peroxide producers have indicated an industry trend towards container reuse. We consider these thicknesses to therefore be most relevant. Under ambient and above temperature conditions, it is expected that inhomogeneous aerobic oxidation will occur in plastic reusable containers, based on the work of Billingham [24]. Consequently, to help insure that results from accelerated testing experiments using small test containers (specimens) are valid for larger containers, such as 55 gallon drums or 5 gallon jerricans, not only must the test container (specimen) wall thickness scale to the thickness of the real end-use product, it must also be of a thickness that preserves the original ratio of aerobic to anaerobic oxidation regions characteristic of the real end-use container. In other words, the use of overly thin or thick test specimens for predicting container polymer oxidation will in all likelihood give erroneous results.

Secondly, though the solubility of oxygen in pure polyethylene is low, under conditions of high peroxide solvent permeability, oxygen permeability is expected to also increase. Under these conditions, a concentration build-up of polyethylene hydroperoxide deeper into the container wall interior would be anticipated. The net result of this condition may be more uniform aerobic oxidation throughout the container wall thickness and a heightened concern for interior auto-catalytic degradation.

\subsubsection{Chain Structure Chain structure can have a profound impact on polyolefin oxidation.} For example, branching will not only introduce highly oxidizable tertiary $\mathrm{C}-\mathrm{H}$ bonds but it can also decrease crystallinity and increase the fraction of oxidizable polymer. These effects become readily apparent in comparing the oxygen uptake for poly(4-methyl-1-pentene) versus linear polyethylene at $100^{\circ} \mathrm{C}$. In the former material, a nearly limiting oxygen uptake of $370 \mathrm{~mL} / \mathrm{g}$ is reached after $150 \mathrm{~h}$ in contrast to less than $50 \mathrm{~mL} / \mathrm{g}$ for polyethylene after

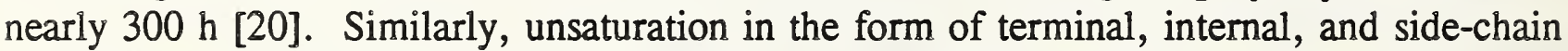
double bonds can affect the rate of oxidation. All of these species, present possibly from the onset or after oxidation has commenced, result in more highly acidic $\alpha$-methylene $\mathrm{C}-\mathrm{H}$ bonds making them more prone to oxidative attack.

Effects of tacticity and pre-existing crosslinking can indirectly affect oxidative stability. In both situations, degree of crystallinity becomes the root parameter, frequently increasing in stereo-regular versus atactic polymers and decreasing as a result of crosslinking. Another consequence of cross-linking will be reduced oxygen permeation.

\subsubsection{Impurities Low level impurities can have a marked impact on oxidative stability in} two possible ways. Firstly, because of catalytic or cooperative interactions, accelerated oxidation rates are frequently observed. Secondly because of exclusionary effects of impurities during polymer crystallization, a concentration buildup of impurities at crystallineamorphous interfaces occurs.

Regarding the first concern, the most problematic impurities are free metal or metallic salts present in the nascent polymer. These metals may be residues from the polymerization initiator system or may be contaminants from resin processing. Hansen et al. [24] found that in the thermal oxidation of polypropylene trace amounts of oxidized copper had a catalytic 
effect on the induction period of oxidation, reducing from $145 \mathrm{~min}$. for the pure polymer to $35 \mathrm{~min}$ for copper dust contaminated polymer at $130^{\circ} \mathrm{C}$ (section 4.3.2). A more serious consequence of metal contamination is the catalytic decomposition effects they have on many classes of organic peroxides. A number of heavy metal ions, primarily those having two or more valency states with a suitable oxidation-reduction potential between them, can react with hydroperoxides, for example, to produce free radicals ( $\mathrm{RO} \bullet$ ), hydroxy anion $\left(\mathrm{OH}^{-}\right)$, and oxidized metal $\left(\mathrm{M}^{+(\mathrm{a}+1)}\right)$. In a study of powdered polypropylene oxidation in the presence of metallic salts of fatty acids the order of decreasing catalytic effect, assessed from oxygen absorption curves and energies of activation, was:

\section{$\mathrm{Co}>\mathrm{Mn}>\mathrm{Cr}>\mathrm{Fe}>\mathrm{V}>\mathrm{Ni}>\mathrm{Ti}>\mathrm{Al}>\mathrm{Mg}>\mathrm{Ba}[20]$.}

Reich et al. [25] established from the oxidation of polypropylene, a direct correlation between the oxidation-reduction potential and the oxidation of polymer as measured by the presence of carbonyl groups.

A further complication of metal contamination arises during polymer processing and melt crystallization. During cool-down after container manufacture, crystallization into spherulites that are free of impurities will occur. Boundary regions surrounding the growing crystallites will develop increasing concentrations of all non-crystallizable components, including trace metals. Since oxidation preferentially occurs within the amorphous regions of the polymer, localized high metal concentrations may cause premature dissociation of peroxide compounds at these interfaces. This problem will be most severe under conditions of high, solvent-assisted or unassisted peroxide permeability.

\subsection{OXIDATIVE STABILIZATION OF POLYETHYLENE}

Because of the inherent oxidative instability of polyolefins, commercial resins are always compounded with antioxidants and photo-stabilizers to help guard against oxidative degradation during processing and under end-use conditions. In this report, "antioxidant" is understood to refer to compounds intended to stabilize polymers against the effects of oxygen at high temperatures, and "photo-stabilizer" refers to compounds that guard against photon induced degradation and operate either by simple ultra-violet absorption or through a free radical chain-breaking mechanism.

As discussed in section 4.4, the auto-oxidation of polyolefins is a chain reaction in which, depending on temperature and oxygen concentration, the chain carriers are alkyl $\left(R^{\bullet}\right)$, alkoxy $(\mathrm{RO} \bullet$ ), and alkylperoxy $(\mathrm{ROO} \bullet$ ) radicals. Compounds which act to trap any of these species will act to stabilize the polymer. It is important to note that we will only address the question of thermal induced polymer degradation and will not consider the conditions, mechanisms, or materials relating to the photolytic stabilization of polyethylene. Concern for ultra-violet exposure will only enter as it relates to the UV catalyzed photodecomposition of organic peroxides that may permeate through the container wall to the exterior surfaces.

\subsubsection{Classification of Antioxidants Antioxidants are designed to inhibit specific steps in} the free radical chain autoxidation process, i.e. interrupt and suppress either the initiation or 
propagation steps (Section 4.4.1) of molecular degradation. Antioxidants are frequently classified on the basis of their ability to do either or both [26]. Compounding multiple antioxidants of various types into polyolefins is frequently performed because of synergism between antioxidants.

Initiation Inhibitors Two main classes of antioxidants inhibit the initiation step in thermal autoxidation. They include peroxide decomposers, materials that decompose hydroperoxides (reaction 4.2 , species III) by polar reactions and metal deactivators, metal ion complexing agents that inhibit other metal catalyzed initiation (section 4.5.3) reactions.

Antioxidants that decompose hydroperoxides include sulfides, aryl and alkyl phosphites, metal salts of some dithioacids, and organophosphites. The exact mechanism of sulfide inhibition is yet to be established. It is believed that the metal deactivators act to tie up specific coordination sites of metal impurities thereby blocking interactions with, and decomposition of peroxides.

Propagation Inhibitors Agents that interrupt propagation reactions (reactions 4.2-4.6) markedly reduce the oxidation rate by limiting the kinetic chain length of the radical reaction. The most important commercial antioxidants that function in this way are hindered phenols and secondary alkylaryl- and diaryl-amines.

The mechanism of action of this most widely recognized group of antioxidants, the chain-breaking (CB) antioxidants, is well understood. It is seen to involve the deactivation of chain-carrying alkylperoxy (Reaction 4.1 , species II) by electron donors, ie. phenols and aromatic amines [27]. The mechanism involves hydrogen atom transfer from the antioxidant (A) to the peroxy radical in a rate controlling step (reaction 4.12). A second peroxy radical is then often trapped by adduct formation (reaction 4.13).

$$
\begin{gathered}
\mathrm{AH}+\mathrm{ROO} \bullet \mathrm{A} \bullet+\mathrm{ROOH} \\
\mathrm{A} \bullet+\mathrm{ROO} \bullet \rightarrow \mathrm{AOOR} \\
2 \mathrm{~A} \bullet \rightarrow \mathrm{A}-\mathrm{A}
\end{gathered}
$$

Table 4.7 lists CB antioxidants widely used in the polymer industry. None of these compounds are effective as UV stabilizers, and in fact undergo photo-induced rearrangement which essentially deactivates the compound. More recently, photolytically stable CB antioxidants (CB/UV) (Table 4.7) have found use in various polyolefins as both UV stabilizers and $\mathrm{CB}$ antioxidants.

\subsubsection{Compounding with Polyethylene There are numerous different commercial} antioxidants that have been developed for use with thermoplastics, thermosets, elastomers, and adhesives. Again, these include amines, phenols, phosphites, sulfides, and metal salts of dithioacids. Table 4.8 lists many of the commercial antioxidants currently in use.

Conversations with both polyethylene resin producers and container manufacturers indicate that antioxidants are always compounded with the polymer at the resin production 
stage, with further compounding sometimes occurring just prior to container molding. It is also clear from our conversations, that information encompassing specific antioxidants and their levels of use within a resin or drum is considered proprietary and not subject to disclosure. However, it does appear that phenol, amine, thioesters, and phosphites are all used in HDPE stabilization [28]. Consequently, at this time, we still know little about the likelihood that a particular resin formulation may be more well suited than a competing resin formulation for eventual use as an organic peroxide containing drum. Such information may indeed further enhance the use of polyethylene containers with these types of aggressively oxidizing compounds. 
CB ANTIOXIDANTS

BHT

Ionol

Irganox 1076

Nonox́ OD

Santoflex IP

\section{UV/CB ANTIOXIDANTS}

Tinuvin 121

Cyasorb 2908

Irganox 2002
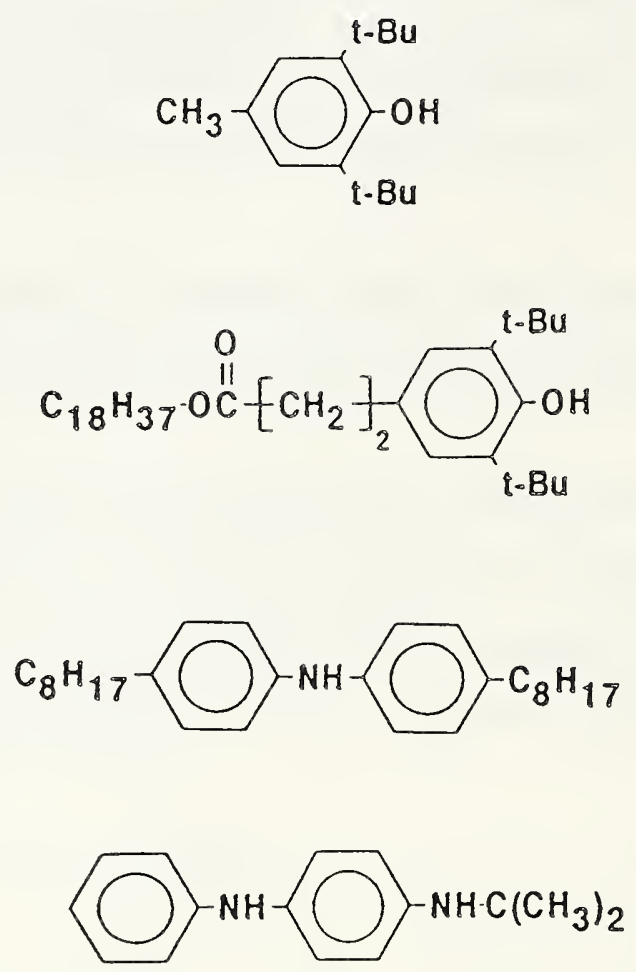

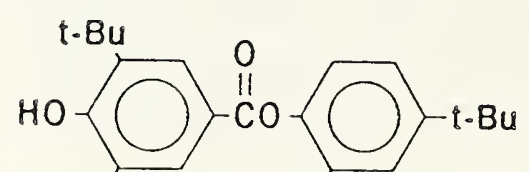

$$
\text { 酶 }
$$


Table 4.8

Commercial Antioxidants [26]

General Trade

Manufacturer

Classification

Name

Aceto PBN

AgeRite

Akrochem

Antioxidant

Alkanox

Aminox

Annullex

Anox

Antigene

Antioxidant

Antox

Aranox

Arbestab

Arrconox

Ashland

BB10

Betanox

Bisoxol

BLE

BXA

CAO

Copper Inhibitor

Cyanaflex

Cyanox

D-1282

DBEP

DBPC

Ethyl

Flectol
Aceto Chem.

R.T. Vanderbilt

Akron Chem.

Bozzetto

Uniroyal

BTP Cocker

Bozzetto

Sumitomo

Anchor Chem.

Rashig

Reichnold Chem.

American Cyanamid

Uniroyal

DuPont

Uniroyal

Robinson Bros.

Uniroyal

Ashland Chem.

Soc. Franc. d'Organo

Synth.

Uniroyal

CdF Chimie

Uniroyal

Uniroyal

Ashland Chem.

DuPont

American Cyanamid

American Cyanamid

Uniroyal

Soc. Franc. d'Organo

Synth.

Soc. Franc. d'Organo

Synth

Ethyl Corp.

Monsanto amine

amines, phenols, phosphites

phenols

phosphites

amine

phenols

amines, phenols

amines, phenols, phosphites, sulfides

amines, phenols

phenol

phenols

phenols

phenols, phosphites

amines

amine

sulfides

amines, phenols

phenol, sulfides

phenol

amine

phenols

amines

amine

phenols

amine

amines

amines, phenols, sulfides

amine

phenol

phenol

phenols

amines 
Table 4.8 (continued)

Commercial Antioxidants [26]

General Trade

Manufacturer

Classification

Name

Flexamine

Good-rite A.O.

IBX

Irganox

Isobutyl Niclate

JZF

Ken-React

MBP5

Montaclere

MTBX

Methyl Niclate

Naugalube

Naugard

Naugawhite

Nevastain

Nocceler

Nocrac

Nonox

Octamine

PC7

Pennox

Phosclere

Plastanox

Polygard

Polylite

Ralox

Rio Resin

Robac

Sandostab

Santoflex
Uniroyal

B.F. Goodrich

Soc. Franc. d'Organo

Synth.

Ciba-Geigy

R.T. Vanderbilt

Uniroyal

Kenrich Petrochem.

Soc. Franc. d'Organo

Synth

Aceto Chem.

Montsanto

Soc. Franc. d'Organo Synth.

R.T. Vanderbilt

Uniroyal

Uniroyal

Uniroyal

Neville Chem.

Ouchi-Shinko

Ouchi-Shinko

ICI

Alk.Chem.Corp. India

Uniroyal

Soc. Franc. d'Organo

Synth.

Pennwalt

Akzo Chemie

American Cyanamid

Uniroyal

Uniroyal

Raschig

R.T. Vanderbilt

Robinson Bros.

Sandoz

Monsanto

\section{amine}

amines, phenols, phosphites

phenol

phenols, sulfide

dithioacid, metal salt

amine

phosphites

phenol

phenol

phenol

phenol

Dithioacid, metal salt

amines

amines, phenols, phosphites sulfides

phenols

phenols

amine

amines, phenols

amines, phenols

amines, phenols

amines

phenol

amines

phosphites

phenol

phosphites

amine

phenol

resin

dithioacid, metal salt

phosphonite

amines 
Table 4.8 (continued)

Commercial Antioxidants [26]

General Trade

Manufacturer

Classification

Name

Santonox

Santovar

Santowhite

Stabilite

Sunnoc

TB

Tenox

Topanol

UV Chek

Vanlube

Vanox

Vulkanox

Weston

Wingstay

Wytox

Zalba
Monsanto

Monsanto

Monsanto

Reichold

Ouchi-Shinko

Soc. Franc. d'Organo

Synth.

Aceto Chem.

Eastman Chem.

ICI

Ferro Corp.

R.T. Vanderbilt

R.T. Vanderbilt

Bayer; Mobay

Borg-Warner

Goodyear

Stepan Chem.

DuPont

Mobil Chem. sulfide

phenol

phenols

phenols

phenols

phenol

phenol

phenols

phenols

phenol

amines

amine, phenols, phosphites

amines, phenols

phosphite

amine, phenols

amines, phenols, phosphites

phenol

phosphites 


\subsection{ASSESSING POLYETHYLENE OXIDATION}

The ultimate problem associated with the degradation of any polymer is failure of the product to meet the specifications required for the products use. Frequently, mechanical breakdown is one such criteria by which failure is assessed. Consequently, testing methods which are sensitive to the deterioration of the principal mechanical property becomes the most practical tool for assessing polymer oxidation. Most commonly, because of limitations on time or material reactivity, accelerated oxidation testing at elevated temperatures, ie. $\geq 70^{\circ} \mathrm{C}$ is conducted. Under conditions of accelerated testing, care must be taken that physical form does not erroneously influence the results. For example, film samples will need to be of a proper thickness to preserve the same oxygen diffusion limitations characteristic of the real end-use container when assessing the plastic containers compatibility with peroxides.

\subsubsection{Testing Methods Numerous testing methods have been used for monitoring the} chemical degradation of polyolefins. They may be categorized according to whether the physical, chemical, thermal, spectroscopic, or mechanical properties are being examined.

Physical Methods: One physical method widely used is the oxygen uptake experiment whereby oxygen absorption is monitored under constant temperature and pressure. This is well suited for studying oxidation initiation. Samples which are either stabilized or unstabilized may be examined in powder, granular, or film macromorphologies. In practice, this technique is rather difficult to perform, requiring very stable temperature control over the course of the experiment which may last several weeks. Also, from the point of view of organic peroxide induced polyethylene deterioration, initiation by oxygen is not a parameter of high concern.

Another physical method very widely used is the variation in melt flow index (MFI) of molten polymer as a result of oxidation. Though imprecise, MFI monitors polymer molecular weight by measuring the melt viscosity of the material. In practice, measurement of polymer molecular weight is a very sensitive indicator of molecular degradation since oxidation reactions will lead to both scission and cross-linking, altering in fact the molecular weight distribution and its mean. A complicating factor of this technique is the elevated temperatures needed to conduct the measurement, generally $190^{\circ} \mathrm{C}$ for polyethylene. Consequently, prolonged MFI testing will lead to continued oxidation of partially oxidized polymer giving erroneous results.

Chemical Methods: As mentioned, molecular weight and molecular weight distribution in particular is a very sensitive parameter for monitoring polymer degradation. Consequently, an ideal technique is gel permeation chromatography (GPC). Unlike MFI, continued oxidation does not complicate this technique, and unlike MFI, GPC does allow molecular weight distribution analysis.

A second highly sensitive and accurate technique is to measure the actual peroxide content using the iodometric technique. This involves deactivation of peroxy groups by iodide titration of powders or thin films. Because this method requires permeation of the 
specimens and adequate time for full diffusion. Generally, swelling solvents are used in conjunction with this test.

Thermal Methods: Conventional thermal methods like differential scanning calorimetry (DSC), differential thermal analysis (DTA), or thermal gravimetric analysis (TGA) have often times been applied to study elevated temperature, accelerated polyethylene oxidation.

Because of a lack of suitable standards, these techniques are not well suited for determining oxidation levels though they can easily be used to rank the oxidative resistance of one sample relative to another.

Spectroscopic Methods: In practice, infra-red (IR) spectroscopy has been the most widely used spectroscopic technique applied to the study of polymer oxidation. Secondary to this is ultra-violet/visible (UV/Vis) spectroscopy. In the former technique, the concentration buildup of oxidation products can be easily measured using minimal sample quantity. The traditional method for assessing oxidation in polyolefins is the carbonyl index which monitors the build-up of non-volatile secondary oxidation products such as ketones, aldehydes, and carboxylic acids. Simultaneously, other secondary products such as $-\mathrm{OOH},-\mathrm{OOR},-\mathrm{C}=\mathrm{C}-$, $\mathrm{OH}$ may also be measured. To enhance the sensitivity of the IR technique to measure -O-Ocontent, reaction with sulfur dioxide has been shown to yield important, low level oxidation data in the $20-300 \mathrm{ppm}$ range [29]. UV/Vis spectroscopy may also be used to follow polymer oxidation though its low sensitivity to $-\mathrm{C}=\mathrm{C}$ - absorptions does not make it well suited for low or intermediate levels of oxidation.

Mechanical Methods: Polyethylene mechanical failure occurs because degradation leads to chain scission and cross-linking in the accessible, amorphous regions of the semicrystalline morphology. Whilst measurements of oxygen absorption, carbonyl content, or molecular weight give much molecular information during oxidation, they may not be very good predictors of mechanical failure. Consequently, mechanical testing techniques following ASTM guidelines for measuring tensile strength, yield stress, impact strength, or stress crack resistance are routinely used in accelerated testing. A $50 \%$ performance loss for multiple samples is the most common criterion for defining failure.

An unfortunate aspect of these methods is that by the time changes in mechanical properties become apparent, the samples are well on their way to failure. In other words, a serious disadvantage of using mechanical property measurements for evaluating oxidative stability is their intrinsic inability to detect the build-up of pre-chain scission or cross-linked oxidation products which can then catalytically decompose to cause rapid and perhaps unexpected product failure.

\section{DISCUSSION OF THE EUROPEAN TEST METHODS}

As noted earlier, the European test methods are based on the use of six standard liquids. The tests consist of three laboratory procedures which compare the behavior of a filling substance to that of the standard liquids. 
(1) Laboratory method A is intended to determine the degree to which polyethylene is swollen by a filling substance. For this purpose specimens of the polyethylene are stored in the filling product at $40^{\circ} \mathrm{C}$ and the weight gain determined as a function of time until a constant weight is obtained. The percentage weight gain is then compared to that for three of the standard liquids, acetic acid, normal butyl acetate and mineral spirits. If the maximum weight gain of the filling substance is less than that for acetic acid, it is assigned to that standard liquid. If the weight gain is larger than that of acetic acid, but less than that of normal butyl acetate, it is assigned to the normal butyl acetate standard, and so on. If, on the other hand, the weight gain is even larger than that for the mineral spirits, for which the swelling is the greatest of the three standard liquids, then compatibility can be demonstrated only by storage for 180 days at $21^{\circ} \mathrm{C}$.

(2) Laboratory method B describes the method known as the Pin Impression Method ISO 4600 referred to earlier under Section 3. In this method, a flat specimen cut from a finished container is both drilled with a hole and milled to give a notch. This is followed by 21 days of storage at $40^{\circ} \mathrm{C}$ in the filling product to be assessed and in the standard liquid (wetting solution). After the preliminary storage, a pin having a diameter 1 millimeter larger than the diamter of the drill hole is pressed in. The specimens subjected to an external stress in this way are then returned to the liquids at $40^{\circ} \mathrm{C}$. The crack formation behavior caused by the action of the surrounding media as a function of the storage time is then determined comparatively. After storage in both the filling substance and the standard wetting solution for various periods of time, the specimens are then removed and part of the specimen cut off so that only the portion between the notch and the hole remains. This portion of the specimen is then subjected to a tensile test in order to determine the residual tensile strength. Again, if the filling substance is found to be more aggressive than the standard wetting solution, compatibiity can only be demonstrated by storage for 180 days at $21^{\circ} \mathrm{C}$.

(3) Laboratory method C applies a standardized test procedure for the determination of the melt flow rate of polyethylene after storage in a 55\% nitric acid solution. This method establishes the extent to which polyethylene is attacked oxidatively. As degradation proceeds, the melt flow rate increases. If in this test the melt flow rate of the specimens stored in the filling substance increases more rapidly than that of the specimens stored in the nitric acid solution, storage for 180 days is required to demonstrate compatibility.

This set of three test methods and six standard liquids are intended to address the three major areas of concern with respect to the compatibility of polyethylene with hazardous materials in the form of liquids: swelling and permeation, environmental stress cracking, and oxidative degradation.

\section{RECOMMENDATIONS}

The central task of this project has been to determine the feasibility of substituting a set of standard liquids for the purpose of compatibility testing of liquid hazardous materials 
with polyethylene. Current DOT regulations require the testing of each individual lading. The use of a standard liquid in place of groupings of hazardous liquids is based on the European approach to testing which calls for the use of one or more of the following six standard liquids: [Wetting Solution, Acetic Acid, Normal Butyl Acetate, Mixture of hydrocarbons (mineral spirits), Nitric Acid, and Water.] The standard liquid approach does appear to address the three principal areas of concern with respect to the compatibility of liquid hazardous materials with polyethylene.

\subsection{COMPATIBILITY TESTING FOR PERMEATION AND/OR SWELLING}

In work done in the 1960's an empirical approach was developed whereby it was found possible, using a large data base, to determine a simple correlation between measured values of mass loss from standard polyethylene bottles and certain properties of the permeant molecules. This approach is known as the "Permachor" scheme [2]. Using this scheme as a basis of our work, the permeation factors of twenty-two organic liquids, including normal butyl acetate and acetic acid, were determined at three different temperatures, 23 , 50, and $60^{\circ} \mathrm{C}$. The Permachor number of each liquid was then calculated based on the earlier work and the logarithm of the permeation factor plotted versus the Permachor number for each of the three temperatures. Qualitatively, agreement with the earlier work was demonstrated, however quantitatively there were differences. In the earlier work the slope of the straight line (best fit) was found to be a constant value of -0.22 and independent of the temperature. In the present work the slope was found to vary from -0.19 at $23^{\circ} \mathrm{C}$ to -0.16 at $60^{\circ} \mathrm{C}$. It does appear that the empirical approach known as the Permachor scheme is sufficiently reliable for estimating the permeation factors of many different liquid hazardous materials and for ranking the severity of individual members within a class of materials.

In addition to the more than twenty organic liquids, permeation factors were also determined for nine different types of mineral spirits obtained from three major suppliers. One commonly used means of ranking mineral spirits is based on their flash point. The general trend is the higher the flash point the lower the permeation factor. However, for one of the three manufacturers the reverse was found to be true. Using the plots obtained for the twenty-two organic liquids, an average Permachor number was determined for each of the nine mineral spirits. These values ranged from as low as 11.6 to as high as 17.2. On the assumption that the regulations will continue to allow testing at a temperature as high as $60^{\circ} \mathrm{C}$, it would appear that only one of the nine types of mineral spirits tested would be suitable as a standard liquid at all three test temperatures (Permachor number of 11.6) and at the same time satisfy the three specifications given in the European regulations. This one type of mineral spirits is the one that would appear to be in reverse order from the others. The others either have too low a flash point or too high a Permachor number, or both. A Permachor number of 11.6 is equivalent to having a mixture of normal dodecane and normal tridecane. Ideally as a standard liquid one would like to have a liquid with a Permachor number less than ten in order to maximize the size of the class of liquids for which it can be substituted. Some advantage may be gained by the addition of aromatic compounds such as 1,2,3,4-tetramethylbenzene (9.4), although cost will at some point become an important factor. 
One area that may merit further investigation is whether or not the specifications on the mixture of hydrocarbons allowed under the European regulations are sufficient to ensure that the average Permachor number for mixture will be less than some specified value, for example 12 or 13 .

\subsection{TEST METHODS TO EVALUATE THE STRESS CRACKING OF POLYETHYLENE}

Environmental stress-crack resistance (ESCR) represents one of the three major areas of concern with respect to the compatibility of liquid hazardous materials with polyethylene. Therefore an ESCR test represents an important aspect to the qualification procedure. In the course of this work, we have described three different test methods which can be used to evaluate the stress-crack resistance of various polyethylenes. Two of the tests are ASTM test methods and one is an ISO test method preferred in Europe. The three test methods are quite diverse in nature and each is preferred by one group or another. ASTM D 1693-70 Standard Test method for Environmental Stress-Cracking of Ethylene Plastic appears to be the simplest test of the three in terms of equipment and time, whereas the ISO 4600 Pin Impression Method may be the most elaborate. It does, however, appear to have the advantage that the tensile strength is monitored as a function of time. This property may indicate the onset of degradation in the mechanical performance before the appearance of visible cracks occurs. In the event that a system of laboratory test methods involving standard liquids similar to those being used in Europe should be adopted, then a test such as the ISO 4600 test method, which is complimentary to the other two laboratory methods in which comparisons are made between the behavior of polyethylene in both the test liquid and the standard liquid, would appear appropriate.

\subsection{PEROXIDE TESTING}

\subsubsection{Permeation of Organic Peroxides and their Solvents As discussed, the Permachor} method for predicting permeation may provide an important tool for assessing the permeation compatibility of commercial organic peroxide formulations with polyethylene packaging. However, before this technique can be reliably applied, there are three important points which need to be clarified.

From our investigations, it has become increasingly evident that for virtually all classes of organic peroxides, chemical structures containing single and multiple short-chain branching sites are extremely common. They include tertiary butyl, isobutyl, tertiary amyl, and isopropyl groups. Of these, tertiary butyl and tertiary amyl branch sites predominate. Unfortunately, as discussed in section 4.2.1, Salame did not adequately examine the impact short chain branch sites has on the permeation of low molar mass liquids through polyethylene. In light of this and the pervasiveness of these groups in the realm of organic peroxides, we envision that further work to test the permeation of molecules containing single and multiple tertiary butyl branch sites through polyethylene may be necessary. These experiments should use model compounds incorporating chemical functionalities common to organic peroxides. 
In addition, we believe that permeation tests need to be conducted which challenge the substitution assumptions that were used to estimate a peroxy group $\pi$-value. As pointed out, Salame does not include a shift value for the -O-O- bond and consequently, a summation of other functionalities was made and used. Again by using model compounds we believe this may be clarified. A concern entering into the design of these experiments is insuring the safe usage and handling of the organic peroxide. Such experiments are requiring exact planning before they can be initiated.

And lastly, because of the extensive use of polar compounds as solvents for organic peroxides, including solvents capable of hydrogen bonding - such as alcohols - we also believe further permeation experiments need to be conducted to reliably predict permeability of these solvents. In essence, though Salame proposes simple diffusion behavior for these types of materials, many reported examples demonstrated much higher permeation rates than would be predicted based on calculated $\pi$-values.

Once the above points are adequately clarified, we once again envision the substitution of a standard liquid for the actual peroxide or dissolution solvent for assessing the permeation characteristics of a polyethylene package. Such a substitution would not only help to simplify existing 49 CFR Part 173.24 permeation assessment, it would also alleviate inherent safety concerns associated with the elevated temperature testing of organic peroxides. Further funding may be needed to fully address all of these points.

The likelihood that some of the above mentioned candidate organic peroxides may indeed permeate appreciably through HDPE is seen in the work of Loschau and coworkers [30]. In their work, they evaluated the swelling of a HDPE at $40^{\circ} \mathrm{C}$. Of the samples tested, included were low molar mass examples belonging to Classes I, II, IV, and VII were found to cause swelling on a magnitude similar to that of their white spirits. These results validate our earlier stated belief that permeation measurements using examples from Table 4.2 are needed to fully determine whether suitable mineral spirits are available for predicting the permeation of these compounds.

\subsubsection{Failure Prediction Due to Peroxide Induced Oxidation There are numerous} mechanisms by which a plastic container may fail due to extended exposure to common commercial organic peroxide formulations. Ultimately, packaging failure will be defined by excessive permeation or leakage of its contents, or structural failure of the packaging unit itself due to a deterioration in the mechanical properties of the container polymer. It therefore becomes important to develop testing procedures that will address each of these two "general" performance requirements, ie. permeation and mechanical integrity. Section 3.2.3 has discussed a proposed method to evaluate and predict the permeation of organic peroxides and their solvents through polyethylene based on the Permachor method. In a similar manner, a method to assess and predict the deterioration of container strength with time will also need to be developed.

Currently, 49 CFR Part 178 require drop and stacking tests to evaluate container mechanical integrity. Of the two tests, only the stacking test requires specimen ageing before conducting the test. Consequently, it is only the stack test that may detect the results of peroxide induced container oxidation through the appearance of leaks. We believe that existing 49 CFR Part 178 testing methods for assessing long term organic peroxide - plastic 
container compatibility may be too insensitive to adequately assess the deterioration of container strength due to polymer oxidation and do not provide adequate warning to prevent unexpected failure due to auto-catalytic degradation. A more sensitive and safe test may also be required of containers destined for the packaging of liquid organic peroxides or other equally chemically aggressive materials. This recommendation becomes even more important as organic peroxide manufacturers continually move in the direction of container reuse.

Numerous methods have been used to evaluate polymer oxidation (section 4.7.1). Yet, only few examples were found that attempt to correlate chemical changes in the polymer with the physical and mechanical deterioration of the polymer. The most relevant work was that of Henman [29] in which he reports embrittlement of low density polyethylene at a carbonyl group concentration above $0.17 \%$ mole relative to carbon. Also, Grieveson et al. [19] showed that for very thick Ziegler polyethylene specimens, density of $0.947 \mathrm{~g} / \mathrm{cm}^{3}$, at $120^{\circ} \mathrm{C}$ in air, the polymer had reached the end of its useful life before the end of the oxygen induction period. At this point, the specimens had lost $70 \%$ of the original flex values, the inherent viscosity has decreased by $20 \%$, and carbonyl content was rapidly increasing.

Attempts to predict changes in mechanical properties based solely on the degree to which chemical modification has occurred is unrealistic because it neglects the importance of material specific physical factors in determining mechanical properties. However, tests such as infra-red are extremely useful in assessing the degree of oxidation and judging the oxidative resistance of one resin relative to another due to antioxidant and stabilizer compounding. As mentioned earlier, in general, the mechanical properties of polyolefins depend on crystallinity or density, molecular weight, molecular weight distribution, presence of branches, and cross-linking effects. Because current regulations are performance rather than material specific, we believe any such future test needs also to reflect container performance.

In practice, of the numerous physical property measurements possible, tensile strength and ultimate elongation at fracture are the most sensitive and widely used methods for evaluating polyolefin degradation. It is important to note that results from these measurements, monitored as a function of oxidation time, are very dependent on sample size and shape so sample preparation will therefore need to be explicitly standardized. For measuring the build-up of oxidation products, infra-red spectroscopy is the simplest and most accurate technique. As a result, we propose that two tests be used to help develop guidelines that will enable us to assess and predict the compatibility of organic peroxides with polyethylene packagings. These tests will examine both the build-up of oxidation, products and the deterioration of mechanical properties, namely infra-red spectroscopy and tensile testing. Without having the results of chemical compatibility testing between candidate organic peroxides and polyethylene following our recommended methods, it is impossible at to say whether a non-peroxide standard liquid for the purpose of resin testing will be practical. Such a material would be extremely desirable for predicting container performance.

A preliminary indicator highlighting the need for testing to determine premature polymer oxidation and/or mechanical performance deteration can be seen from a recent report by Loschau and coworkers [30]. Following ageing studies $40^{\circ} \mathrm{C}, \mathrm{HDPE}$ samples 
exposed to some of the same organic peroxides listed in Table 4.2 were examined using tensile testing and viscosity measurements. The later technique is highly sensitive to changes in molecular weight as would be expected when polymer is oxidized. Under their test conditions, examples of Classes I and VIII both showed a reduction in PE molecular weight in excess of comparable samples stored with $55 \%$ nitric acid; a standard liquid to date. Both hydroperoxides and peroxyacids decompose to form highly reactive peroxy, alkoxy, and alkyl radicals (see Table 4.4) which are all sufficiently reactive to cause degradation. In light of these results. it is our recommendation that a full examination of the degradation of polyethylene needs to be completed using these and similar organic peroxide compounds especially if container reuse continues to grow within the marketplace. 


\section{REFERENCES}

[1] Development of Test Methods to Determine the Compatibility of Liquid Hazardous Materials with Polyethylene Packagings. NISTIR 4346, May 1990. This report is available from the National Technical Information Service, Springfield VA 22151.

[2] Salame, M., An Empirical Method for the Prediction of Permeation in Polyethylene and Related Polymers, SPE Transactions, 1, No. 4, pp. 1-11 (1961).

[3] NFPA 325M, Fire Hazard Properties of Flammable Liquids, Gases and Volatile Solids, (1984), National Fire Protection Association, Batterymarch Park, Quincy, MA 02269.

[4] ASTM 1990 Annual Book of ASTM Standards, volume 8.02, American Society for Testing and Materials, 1916 Race Street, Philadelphia, PA 19103.

[5] Barnes, J.D., and G.M. Martin, Performance of Plastic Packaging for Hazardous Materials Transportation, Part II, Permeation, Report No. DOT $\backslash M T B \backslash O H M O-77 / 4$, December 1977. This report is available from the National Technical Information Center, Springfield, VA 22151.

[6] ASTM 1990 Annual Book of ASTM Standards, volume 6.03, American Society for Testing and Materials, 1916 Race Street, Philadelphia, PA 19103.

[7] ASTM 1990 Annual Book of ASTM Standards, volume 8.01, American Society for Testing and Materials, 1916 Race Street, Philadelphia, PA 19103.

[8] Crissman, J.M., Journal of Testing and Evaluation, ASTM, July, 273(1983).

[9] D. Swern, ed., Organic Peroxides, Vol. II, John Wiley \& Sons, Inc., New York, 1970.

[10] C.S. Sheppard, O.L. Mageli, in Encyclopedia of Chemical technology, Vol. 17, Kirk, Othmer, eds., John Wiley \& Sons, New York, 1982, pp. 27-90.

[11] Suggested Relative Hazard Classification of Organic Peroxides, Organic Peroxide Producers Safety Division, The Society of the Plastics Industry, Inc., NY, NY.

[12] Half-life time and temperatures reflect the Arrhenius decomposition of a peroxide compound and corresponds to the time (temperature) require to decompose one-half the peroxide originally present at a given temperature (time). It is therefore a relative measure of the activation energy for -O-O-bond dissociation. 
[13] L. Reich, S.S. Stivala, Elements of Polymer Degradation, McGraw-Hill Co., New York, 1971.

[14] D.G. Hendry, T. Mill, L. Piszkiewicz, J.A. Howard, H.K. Eigenmann, J. Phys. Chem., Ref. Data Vol., 3, 937, 1974.

[15] J.C.W. Chien, J. Polym. Sci., 6, 375-379 (1968).

[16] B. Baum, J. Appl. Polym. Sci., 2 (6), 281 (1959).

[17] A. Garton, D.J. Carlson, D.M. Wiles, in Developments in Polvmer Photochemistry, N.S. Allen, ed., Applied Science Publishers, London, 1980, pp. 93-123.

[18] W.L. Hawkins, W. Matreyek, F.H. Winslow, J. Polym. Sci., 41, 1 (1959).

[19] B.M. Grieveson, R.N. Haward, B. Wright, in High Temperature Resistance and Thermal Degradation of Polvmers, Sci. Monographs, Society of Chemical Industries, London, 1961, pp. 413-431.

[20] N.S. Allen, Degradation and Stabilization of Polyolefins, Applied Science Publishers, New York, 1983.

[21] F.H. Winslow, M.Y. Hellman, W. Matreyek, S.M. Stills, Polym. Eng. Sci., $\underline{6}, 273$ (1966).

[22] J.Y. Moisan, in Polymer Permeability, J. Comyn, ed., Elsevier Applied Science Publishers, New York, 1985, pp, 119-176.

[23] N.C. Billingham, P.D. Calvert, in Developments in Polvmer Stabilization, 3rd Edition, G. Scott, ed., Applied Science Publishers, London, 1980.

[24] R.H. Hansen, C.A. Russel, T. De Benedictis, W.M. Martin, J.V. Pascale, J. Polym. Sci., 2, 587 (1964).

[25] L. Reich, B.R. Jadrnicek, S.S. Stivala, J. Polym. Sci., 9, 231 (1971).

[26] P.P. Nicholas, A.M. Luxeder, L.A. Brooks, P.A. Hammes, in Encyclopedia of Chemical Technology, Kirk, Othmer, eds., Wiley \& Sons, New York, 1978, pp. 128148.

[27] G. Scott, in Advances in Polvolefins, R.B. Seymour, T. Cheng, eds., Plenum Press, New York, 1987. 
[28] Chemical Additives for the Plastics Industry, Radian Corp., McLean, VA, 1987, pp. 18-23.

[29] T.J. Henman, in Developments in Polymer Degradation, Vol. 6, N. Grassie, ed., Elsevier Applied Science Publishers, New York, 1985, pp. 107-145.

[30] G. Loschau, D Lemke, D. Cramer, W. Meister, Compatibility Tests for Dangerous Goods Packaging made of High Molecular Weight, High Density Polyethylene for Organic Peroxides belonging to Class 5.2, Verpackungsrundschau, Vol. 39, No. 7, (1988). 
NIST-114A

(REV. 3-90)
U.S. DEPARTMENT OF COMMERCE NATIONAL INSTITUTE OF STANDARDS AND TECHNOLOGY

BIBLIOGRAPHIC DATA SHEET
1. PUBUCATION OR REPORT HUMBER NISTIR 4729

2 PERForming ORGAMIZATION REPORT HUMBER

3. PUBUCATION DATE

December 1991

\section{TITLEAND SUBTTILE}

Development of Test Methods to Determine the Compatibility of Liquid Hazardous

Materials with Polyethylene Packagings

5. AUTHOR(S)

J.M. Crissman and M.A. Schen

6. PERFORMINO ORGANIZATIOH (IF JOINT OR OTHER THAN NIST, SEE INSTRUCTIONS)

U.S. DEPARTMENT OF COMMERCE

MATIOHAL INSTITUTE OF STANDARDS AND TECHMOLOOY

CATHERSBUAG, MD 2089

7. CONTRACT/GRANT NUMBER

DTRS $-56-90-\mathrm{X}-70006$

8. TYPE OF REPORT AND PERIOD COVERED

Final 6/01190-12/31/91

9. SPONSORING ORGAHIZATION MAME AND COMPLETE ADDRESS (STAEET, CIT, STATE, ZP)

U.S. Department of Transportation

Research and Special Programs Administration

Office of Hazardous Materials Transportation

10. SUPPLEMENTARY MOTES

11. ABSTRACT (A 200-WORD OR LESS FACTUAL SUMMARY OF MOST SIGNIFICANT INFORMATIOM. IF DOCUMENT INCLUDES A SIGNIFICANT BIBUOGRAPHY OR LTERATURE SURVEY, MENTION IT HERE)

This report describes work done for the Department of Transportation, Office of Hazardous Materials Transportation. to develop test methods which can be used to determine whether a liquid hazardous material may be shipped in a specific type of polyethylene container. Current federal regulations require that each prospective lading be tested individually in proposed polyethylene packagings. The central task of this project is to determine the feasibility of substituting a set of standard liquids for the purpose of compatioility testing with polyethylene. In determining the compatibility of hazardous liquids with polyethylene there are three major areas of concern, permeation and/or swelling, environmental stress cracking, and oxidative degradation. Specific recommendations are made for a set of standard liquids which address all three aspects of compatibility. Special attention is given the class of organic peroxides which may be unstable at the test temperatures currently in use. In the area of permeation, an empirical method known as the "Permachor" scheme is proposed as a means of estimating the permeability of many liquid hazardous materials, and for ranking individual members within a given class of liquids.

12 KEY WORDS (6 TO 12 ENTRIES; ALPHABETICAL ORDER; CAPTALZE ONLY PROPEA MAMES; AND SEPARATE KEY WORDS BY SEMICOLONS)

Compatibility, hazardous materials, organic peroxides, Permachor, permeation, polyethylene, standard liquid 


